\title{
Modeling the airborne particle complex as a source-oriented external mixture
}

\author{
Michael J. Kleeman and Glen R. Cass \\ Environmental Engineering Science Department, California Institute of Technology, Pasadena
}

\section{Annmarie Eldering}

Civil and Environmental Engineering, University of Iowa, Iowa City

\begin{abstract}
A Lagrangian air quality model is developed which represents the airborne particle complex as a source-oriented external mixture. In a sourceoriented external mixture, particles of the same size can evolve to display different chemical compositions that depend on the chemical and hygroscopic properties of the primary seed particles initially emitted from different sources. In contrast, previous models initialize the airborne particles as an internal mixture in which all particles of the same size are assumed to have the same chemical composition. Test cases show that representation of the aerosol as an internal mixture can distort the predicted particle composition and concentration in the $\mathrm{HNO}_{3} / \mathrm{NH}_{3} / \mathrm{HCl} / \mathrm{H}_{2} \mathrm{SO}_{4} /$ aerosol $\mathrm{Cl}^{-} / \mathrm{SO}_{4}^{-} / \mathrm{NO}_{3}^{-} / \mathrm{NH}_{4}^{+} / \mathrm{Na}^{+}$system when $\mathrm{Na}^{+}$and $\mathrm{SO}_{4}^{-}$exist in separate particles, as may occur when sea spray coexists with long-distance transport of anthropogenic sulfates. Tests also indicate that the external mixture model can predict the evolution of a nearly monodisperse aerosol into a bimodally distributed aerosol as relative humidity increases, qualitatively matching observations. The sourceoriented external mixture model is applied to predict the size and composition distribution of airborne particles observed at Claremont, California, on August 28, 1987. Calculations produce an aerosol mass distribution that is distinctly bimodal in the size range from $0.1 \mu \mathrm{m}$ to $1.0 \mu \mathrm{m}$ particle diameter, matching field observations. External mixture calculations also predict specific differences in composition between particles of the same diameter. The external mixture model is expected to have applications including exploration of the cause of the particleto-particle differences seen by time-of-flight mass spectrometers that measure single particle size and composition in the atmosphere.
\end{abstract}

\section{Introduction}

Mechanistic air quality models are presently being formulated that track primary emissions of particles and gases in the atmosphere as these pollutants undergo dilution, chemical reaction, gas-to-particle conversion processes, and deposition at the Earth's surface [Seigneur et al., 1986; Pilinis and Seinfeld, 1988; Hudischewskyj and Seigneur, 1989; Middleton and Burns, 1991; Pandis et al., 1993; Binkowski and Shankar, 1995; Eldering and Cass, 1996]. These models seek to predict the size distribution and chemical composition of ambient particles, and from such information, predictions of radiative transfer through the atmosphere can be made. Accurate calculations of the effect of source emissions on particle size and composition are important for under-

Copyright 1997 by the American Geophysical Union.

Paper number 97JD01261.

0148-0227/97/97JD-01261\$09.00 standing how to control urban/regional visibility problems [National Research Council (NRC), 1993] as well as the large-scale effects that air pollutants can have, such as climate forcing [Charlson et al., 1992; Penner et al., 1994]. Another important application of detailed aerosol calculations is related to the adverse health effects associated with inhalation of airborne fine particles. While many of the mechanisms that trigger respiratory and cardiac problems in response to airborne particle exposure remain unknown, evaluation of several of the hypotheses advanced to explain the health effects observed depends on being able to account for either the absolute number concentration and composition of ultrafine particles (diameter, $d_{p}<0.1 \mu \mathrm{m}$ [Oberdorster et al., 1995]) or the specific details of individual particle chemical composition such as particle acidity or trace metals content [Schlesinger, 1989; Dreher et al., 1997].

An internally mixed aerosol is defined as one in which all particles of the same size have exactly the same chemical composition. The atmospheric aerosol processes air quality models that have been demonstrated 
to date all initialize the particles as an internal mixture even though several experiments have shown that this assumption may not be accurate. Zhang et al. [1993] used a tandem differential mobility analyzer to demonstrate that the ambient aerosol at Claremont, California, contains particles having different hygroscopic characteristics at the same particle size, suggesting that particles of the same size have different chemical compositions. Ligocki et al. [1990] examined the chemical composition of particles deposited from the atmosphere using a scanning electron microscope equipped with an $\mathrm{X}$ ray spectrometer and also found significant variability in the chemical composition of particles with the same diameter. While previous air quality models using moving size sections to represent the aerosol may develop situations where particles in adjacent size bins begin to overlap in size because of differences in the rate of gas-to-particle conversion processes, the degree of heterogeneity between particles of the same size in those models is still small compared with that measured in the atmosphere by aerosol time-of-flight mass spectrometers [Noble and Prather, 1996].

The purpose of this paper is to demonstrate the properties of an aerosol processes air quality model in which the airborne particles are represented as a sourceoriented external mixture. An externally mixed aerosol is one in which different particles of the same size can have different chemical compositions. In the extreme an external mixture would consist of particles containing only model pure substances, such as pure ammonium sulfate in many particles of one type separated from other particles made entirely of organic compounds or pure elemental carbon. However, such complete segregation of chemical substances is no more realistic than the idealization that all particles are internally mixed. Instead, we conceive of the aerosol as a source-oriented external mixture in which the individual chemical composition of the primary seed particles emitted at their source reflects the possibly complex chemical composition of the effluent from that source. The aerosol then contains particles with different chemical compositions at the same size as seed particles from characteristically different emissions source types enter into the same air parcel and evolve over time.

\section{Model Formulation}

In the present study, the Lagrangian aerosol processes trajectory models developed previously by Eldering and Cass [1996], Russell et al. [1983], and Russell and Cass [1986] are expanded to produce a model capable of representing the ambient aerosol either as an internal or as a source-oriented external mixture of particles. In the model of Eldering and Cass [1996] a countable number of discrete particles, having initial sizes and chemical compositions determined by the source from which they were emitted, are inserted into a vertical stack of computational cells as it is advected across the airshed.
Along a typical trajectory crossing the South Coast Air Basin of California and terminating at Claremont on August 28, 1987, approximately $10^{20}$ particles are emitted into the model. Air parcel trajectories and mixing depths are determined from three-dimensional wind fields and mixing depth fields interpolated from observational data by the methods of Goodin et al. [1979]. Within each computational cell, atmospheric gas-phase chemical reactions are modeled according to the chemical mechanism of Carter [1990] with extensions to track condensible organic gases that may form secondary organic aerosol [Pandis et al., 1992]. Diffusion of gases to and from particles is calculated according to the AIM computer code of Wexler and Seinfeld [1991]. Dry deposition of particles as a function of size is calculated from atmospheric boundary layer theory, as is dry deposition of reactive gases. An approximate fog model is used to track sulfate formation within fog droplets due to $\mathrm{SO}_{2}$ oxidation in the aqueous phase by dissolved hydrogen peroxide, dissolved ozone, or dissolved oxygen in the presence of trace metal catalysts.

The processes listed above may be described by a Lagrangian trajectory form of the atmospheric diffusion equation

$$
\begin{aligned}
\frac{\partial G_{j}}{\partial t}= & \frac{\partial}{\partial z}\left(K_{z z} \frac{\partial G_{j}}{\partial z}\right)-\sum_{k} L_{i j}^{k}\left(G, P^{k}, T, \mathrm{RH}\right) \\
& +R_{j}(G, T, \mathrm{RH}) ; \mathrm{j}=1,2, \ldots, \mathrm{n} \\
\frac{\partial P_{i}^{k}}{\partial t}= & \frac{\partial}{\partial z}\left(K_{z z} \frac{\partial P_{i}^{k}}{\partial z}\right)+\sum_{j} L_{i j}^{k}\left(G, P^{k}, T, \mathrm{RH}\right) \\
& +M_{i}^{k}\left(P^{k}, T, \mathrm{RH}\right) ; \mathrm{i}=1,2, \ldots, \mathrm{m}
\end{aligned}
$$

where $G_{j}$ is the gas-phase concentration of species $j$, $P_{i}^{k}$ is the concentration of chemical species $i$ present in particles of type $k, K_{z z}$ is the turbulent eddy diffusivity in the vertical direction $z, L_{i j}^{k}$ is the gas-to-particle conversion rate for gas-phase species $j$ which form aerosolphase species $i$ on particles of type $k, R_{j}$ is the rate of production of gas-phase species $j$ due to gas-phase reaction, $M_{i}^{k}$ is the rate of production of species $i$ within particles of type $k$ due to aqueous-phase chemical reaction, $T$ is the absolute temperature, and $\mathrm{RH}$ is the ambient relative humidity. Pollutant emissions and dry deposition processes are incorporated into the boundary conditions for the ground level cell in the model. Coagulation and nucleation are neglected relative to other processes for the case of the relatively dilute atmospheric systems of interest to regional air pollution problems. Test calculations applied to self-coagulation of an urban aerosol like that studied during the applications in this paper show that the time scale for coagulation is greater than 17 hours, much longer than for other processes in the model. If conditions are encountered elsewhere in which coagulation and nucleation should 
not be neglected, then these processes can be added to the model.

In the original model of Eldering and Cass [1996], particle-phase emissions from each source are internally mixed into the preexisting ambient aerosol when they enter the atmosphere. The purpose of the research described in the present study is to create a sourceoriented external mixture of particles by continuing to differentiate between particles emitted from different sources even after they are released into the atmosphere. This formulation greatly increases the computational burden of the problem, and so efficiency improvements also are necessary to make calculations tractable. Each major feature of the model which differs significantly from the description given by Eldering and Cass [1996] is discussed in the following sections.

\subsection{Emissions Model}

The model of Eldering and Cass [1996] represents particles emitted from a single source type as if they had a discrete distribution where the initial diameters of the primary particles occur at 15 discrete sizes centered at equally spaced logarithmic size intervals spanning the diameter range from $0.01 \mu \mathrm{m}$ to $10 \mu \mathrm{m}$. The number of particles emitted at a given size is calculated using the mass emission rate within each logarithmic size interval for the source under consideration and the particle density calculation method described by Larson et al. [1988]. The size distribution and chemical composition of the particles from each of the major emission source types that occur in an urban area are principally obtained from the source test program conducted by Hildemann et al. [1991a, b], supplemented by other data sources as described by Eldering and Cass [1996].

In the present paper, a source-oriented external mixture of particles is created by differentiating the primary particles emitted from the following source types: catalyst-equipped gasoline engines, non-catalystequipped gasoline engines, diesel engines, meat cooking, paved road dust, crustal material from sources other than paved road dust, and acidic aerosol from industrial processes. Particulate emissions from the remaining sources are combined to produce a single lumped source category having a chemical composition equivalent to the weighted average composition of the many remaining small sources that are grouped together. The individual particles emitted from each of the source types listed above are described in terms of their content of the following chemical components: elemental carbon, organic carbon, sodium, chloride, ammonium, sulfite, sulfate, nitrate, iron (oxidation states II and III), manganese (oxidation states II and III), copper (oxidation states I and II), all remaining metals as a single group, and all other nonmetallic species as a single group. The distribution of iron between oxidation states is represented according to the data of Erel et al. [1993] as $\mathrm{Fe}(\mathrm{II}) / \mathrm{Fe}(\mathrm{III})=51 / 49$ based on analysis of fog water samples taken in the Los Angeles area. The distribution of manganese and copper between possible oxidation states is taken from Jacob et al. [1989] based on measurements made at Bakersfield, California. This distribution is $\mathrm{Cu}(\mathrm{I}) / \mathrm{Cu}(\mathrm{II})=10 / 90$ and $\mathrm{Mn}(\mathrm{II}) / \mathrm{Mn}(\mathrm{III})=$ $600 / 1$. The relative chemical composition of all particles from the same source is assumed to be identical since data that distinguish differences in the composition of particles of different sizes from the same source are not available in general.

Gas-to-particle conversion processes represented within the model require that gaseous pollutant emission data for oxides of nitrogen, volatile organic species, ammonia, and $\mathrm{SO}_{2}$ be supplied to the model. These emissions are represented as described by Harley et al. [1992, 1993a, b] and Eldering and Cass [1996].

\subsection{Vertical Transport and Dry Deposition}

Vertical transport due to turbulent diffusion is specified between five computational cells with thicknesses (beginning at ground level and proceeding upward) of $34.5 \mathrm{~m}, 105.5 \mathrm{~m}, 140 \mathrm{~m}, 330 \mathrm{~m}$, and $390 \mathrm{~m}$ resulting in a modeling region $1000 \mathrm{~m}$ thick. Calculation of the dry deposition of gas-phase pollutants is based on boundary layer theory and land-use specific surface resistances as described by Russell et al. [1993]. Vertical transport of particle-phase species is based on particle number concentrations per cubic meter of air exchanged and is calculated numerically using the Crank Nicholson method as described by Chapra and Canale [1988].

Dry deposition of particles follows the method described by Slinn and Slinn [1980] and Seinfeld [1986] with appropriate modifications to account for the effect of changes in atmospheric stability conditions. The resultant equation for the deposition velocity of particles of type $k, v_{p}^{k}$, may be written as

$$
v_{p}^{k}=\frac{1}{r_{C}^{k}+r_{D}^{k}+r_{C}^{k} r_{D}^{k} v_{s}^{k}\left(a_{d}^{k}\right)}+v_{s}^{k}\left(a_{d}^{k}\right)
$$

with

$$
\left(r_{D}^{k}\right)^{-1}=u_{*}\left[\left(S c^{k}\right)^{-2 / 3}+10^{-3 / S t^{k}}\right]
$$

where $r_{C}^{k}$ is is the resistance to deposition in the constant flux layer, $r_{D}^{k}$ is the resistance in the sublayer immediately adjacent to the ground, $u_{*}$ is the friction velocity, $S c^{k}$ is the Schmidt number for particles of size $k, S t^{k}$ is the Stokes number for particles of size $k$, and $v_{s}^{k}$ is the gravitational settling velocity of particles with aerodynamic diameter $a_{d}^{k}$. In the present study, representation of the resistance term $r_{C}^{k}$ has been improved and depends on atmospheric stability conditions as described by McRae et al. [1982]:

Stable conditions

$$
r_{C}^{k}=\frac{0.74}{k_{V} u_{*}} \ln \left(\frac{z_{r}}{z_{0}}\right)+\frac{4.7}{L k_{V} u_{*}}\left(z_{r}-z_{0}\right)
$$


Neutral conditions

$$
r_{C}^{k}=\frac{0.74}{k_{V} u_{*}} \ln \left(\frac{z_{r}}{z_{0}}\right)
$$

Unstable conditions

$$
r_{C}^{k}=\frac{0.74}{k_{V} u_{*}}\left\{\ln \left[\frac{\gamma_{1}-1}{\gamma_{1}+1}\right]-\ln \left[\frac{\gamma_{2}-1}{\gamma_{2}+1}\right]\right\}
$$

where $\gamma_{1}=\sqrt{1-9 \frac{z_{s}}{L}}, \gamma_{2}=\sqrt{1-9 \frac{z_{0}}{L}}, k_{V}$ is the Von Karman constant, $z$ is elevation above ground level, $z_{r}$ is the pollutant measurement reference height $(10$ $\mathrm{m}), z_{0}$ is the surface roughness height, and $L$ is the Monin-Obukhov length. Values of the surface roughness height $z_{0}$ are obtained from detailed land-use maps as described by Russell et al. [1993].

\subsection{Gas-to-Particle Conversion: Large Aerosol Water Content}

In the present study, the approximate fog model of Eldering and Cass [1996] is replaced by a more exact treatment. The model used to describe liquid-phase chemical conversion under these conditions follows the approach of Jacob [1986] and Jacob et al. [1989]. Dissolution of gas-phase species into the aqueous phase is considered for $\mathrm{NH}_{3}, \mathrm{HCl}, \mathrm{CH}_{3} \mathrm{OH}, \mathrm{HCOOH}, \mathrm{CH}_{3} \mathrm{O}_{2}, \mathrm{CH}_{3} \mathrm{OOH}$, $\mathrm{CH}_{3} \mathrm{C}(\mathrm{O}) \mathrm{OOH}, \mathrm{OH}, \mathrm{HNO}_{3}, \mathrm{H}_{2} \mathrm{O}_{2}, \mathrm{HO}_{2}, \mathrm{O}_{3}, \mathrm{NO}, \mathrm{NO}_{2}$, $\mathrm{NO}_{3}, \mathrm{HNO}_{4}, \mathrm{HCHO}, \mathrm{CHOCHO}, \mathrm{CH}_{3} \mathrm{C}(\mathrm{O}) \mathrm{CHO}, \mathrm{SO}_{2}$, HONO, and $\mathrm{CH}_{3} \mathrm{COOH}$. The rate equation that describes transport between the gas phase and the particle or droplet phase within the fog module is

$$
\frac{\partial P_{i}^{k}}{\partial t}=4 \pi N_{k} D_{i} r_{k} \alpha_{i}\left(G_{i}^{\infty}-G_{i}^{s}\right)
$$

where $P_{i}^{k}$ is the concentration $\left(\mu\right.$ mole $\mathrm{m}^{-3}$ air) of the $i^{\text {th }}$ chemical species within the liquid phase associated with particles of type $k, N_{k}$ is the ambient number concentration of particles of type $k, D_{i}$ is the gas-phase molecular diffusivity of chemical species $i, r_{k}$ is the radius of particles of type $k, \alpha_{i}$ is the accommodation coefficient for collision of gaseous chemical species $i$ with the aqueous phase, $G_{i}^{\infty}$ is the ambient gas-phase concentration of chemical species $i$, and $G_{i}^{s}$ is the gas-phase concentration of chemical species $i$ at the droplet surface. Gas-phase molecular diffusivities are estimated by the method of Wilke and Lee [Reid et al., 1987], when data on boiling points are available, and the method of Fuller, Schettler, and Giddings [Reid et al., 1987], when no data on boiling points are available. The accommodation coefficient for all chemical species is assumed to be 0.1 .

The exchange of $\mathrm{NH}_{3}$ between the gas and the aqueous phases requires special attention at high $p H$ because the aqueous concentrations of $\mathrm{NH}_{4}^{+}$and $\mathrm{H}^{+}$become closely coupled. Since an extremely small time step is required for integration under these conditions, this calculation is done separately from the rest of the equation set to improve numerical efficiency. An explicit form of Euler's method is used to integrate equation (8) for $\mathrm{NH}_{3}$ along with the following equation describing the evolution of aqueous hydrogen ion:

$$
\frac{\partial\left[\mathrm{H}^{+}\right]}{\partial t}=\frac{\partial\left[\mathrm{H}^{+}\right]}{\partial[\mathrm{N}(-\mathrm{III})]} \frac{\partial[\mathrm{N}(-\mathrm{III})]}{\partial t}
$$

where $\left[\mathrm{H}^{+}\right]$is the concentration of hydrogen ion in solution, and $[\mathrm{N}(-\mathrm{III})]$ is the aqueous concentration of $\mathrm{NH}_{3}$ plus $\mathrm{NH}_{4}^{+}$. The gas-phase concentration of $\mathrm{NH}_{3}$ at the particle surface needed in equation (8) is related to aqueous-phase $\mathrm{NH}_{3}$ concentrations via Henry's law for ammonia according to the treatment of Jacob [1986]. The term $\frac{\partial\left[\mathrm{H}^{+}\right]}{\partial[\mathrm{N}(-\mathrm{III})]}$ is calculated using perturbation analysis every time the $p \mathrm{H}$ of a particular droplet shifts by more than 0.5 units.

Species in aqueous solution are acted on by a kinetic reaction mechanism focusing on the oxidation of sulfur via pathways including iron, manganese and copper catalysis in addition to reaction with dissolved $\mathrm{O}_{3}$ and $\mathrm{H}_{2} \mathrm{O}_{2}$. The mechanism consists of 58 active chemical species undergoing 177 reactions while constrained by 29 equilibrium relationships. Temperature corrections to rate and equilibrium constants are made using thermodynamic data from Jacob [1986], Jacob et al. [1989], and Wagman et al. [1982]. Ionic strength corrections to equilibrium calculations are made using the Davies method as described by Stumm and Morgan [1981]. The simultaneous nonlinear equations describing the equilibrium system are solved using the MICROQL technique described by Westall [1979].

When meteorological observations indicate that the air parcel studied is entering a fog, the critical radius and critical saturation ratio for each particle is calculated according to the Kohler equation as described by Pruppacher and Klett [1978]. Those particles with a critical saturation ratio less than the ambient saturation ratio are activated to form fog droplets, while particles with a higher critical saturation ratio are not activated and thus remain as interstitial aerosol. Droplet growth occurs by condensation of water vapor which is calculated according to the method described by Pruppacher and Klett [1978] with data on osmotic coefficients from Robinson and Stokes [1955].

\subsection{Gas-to-Particle Conversion: Small Aerosol Water Content}

In the absence of fog, aerosol liquid water content is small but nonzero during periods when the ambient relative humidity is greater than the relative humidity of deliquescence for the particles in the atmosphere. The gas-to-particle conversion calculations for particles under these conditions are based on the framework of the computer code AIM developed by Wexler and Seinfeld [1991]. During the construction of the model described in this study, it was discovered that the original AIM algorithm does not permit the crystallization of 
solid-phase species as aerosol water content decreases below the point where this should occur under conditions where particles contain more than one possible solid-phase component. This problem was corrected and the convergence criteria for particle-phase equilibrium were altered to ensure that the driving potential for the formation of an additional amount of each solidphase species was zero at equilibrium.

The original version of AIM considers gas-phase water concentrations to be in equilibrium with particlephase concentrations using the Zdanovskii, Stokes, and Robinson (ZSR) method described by Wexler and Seinfeld [1991]. During model development it was discovered that if aerosol water content is treated in a kinetic fashion then the efficiency of the overall solution method could be improved. The equations describing the kinetic exchange of water between the gas and the particle phases are taken from Pruppacher and Klett [1978]. Data on osmotic coefficients are obtained from the original version of AIM with modifications for the electrolytes $\left(\mathrm{NH}_{4}\right)_{2} \mathrm{SO}_{4}, \mathrm{NH}_{4} \mathrm{HSO}_{4},\left(\mathrm{NH}_{4}\right)_{3} \mathrm{H}\left(\mathrm{SO}_{4}\right)_{2}$, $\mathrm{Na}_{2} \mathrm{SO}_{4}, \mathrm{NaHSO}_{4}$, and $\mathrm{NaNO}_{3}$ based on the data of Tang and Munkelwitz [1994]. The original version of AIM uses the Kusik and Meissner method to calculate binary activity coefficients for ion pairs in solution and then uses an alternative approximation to calculate activity coefficients in multicomponent solutions. The method used to estimate the multicomponent activity coefficients was modified to more closely follow the treatment shown by Kusik and Meissner [1978].

\subsection{Gas-to-Particle Conversion: Zero Aerosol Water Content}

During periods of low relative humidity the liquid water shell surrounding atmospheric particles may disappear entirely, leaving a solid particle core exposed to the gas phase. Gas-to-particle conversion may still occur under these conditions, but the flux of acidic gas-phase species to and from the particle must be balanced by the flux of ammonia so that no dissociated species exist in the particle phase. The equations used to describe this process are the same as those used in the original version of AIM, but the conditions when they are applied are modified. The original version of AIM uses equations requiring that the flux of ammonia to the particle exactly balance the net flux of strong acids whenever the ambient relative humidity falls below $78 \%$. In the revised version of AIM, this flux-matching requirement is not imposed until the particle becomes completely solid. The thickness of the liquid water shell surrounding the particle is calculated at each time step. If the water shell becomes thinner than the approximate thickness of 20 water molecules $(5.6 \mathrm{~nm})$, the remaining water is expelled from the particle and the equations for zero water content are used. This modification is important since many particles retain a significant aqueous shell even after the relative humidity falls below $78 \%$.

\subsection{Solution Technique}

The most complicated and time-consuming operations performed during model calculations involve the integration of sets of simultaneous ordinary differential equations describing such processes as gas-phase kinetics / transport / deposition, aqueous-phase kinetics / gas-to-particle conversion, and gas-to-particle conversion during periods of low relative humidity. The numerical solution technique used for all these tasks is based on the hybrid method described by Young and Boris [1977] with several modifications.

The Young and Boris algorithm classifies individual equations in the simultaneous set as either stiff or nonstiff. Nonstiff equations are solved with an implicit form of Euler's method. This technique is simple and easy to apply but suffers from stability problems when the characteristic time for an equation becomes small relative to the time step used by the solution method. To minimize this effect, stiff equations are modeled with the form

$$
\frac{d C(t)}{d t}=a-\frac{C(t)}{\tau}
$$

where $C(t)$ is the concentration of a chemical species at time $t, a$ is the rate of production for the chemical species, and $\tau$ is the time constant for chemical species rate of destruction. If $a$ and $\tau$ are constant with respect to time, this equation can be solved analytically to give

$$
C(t+\Delta t)=a \tau+(C(t)-a \tau) \exp \left(\frac{-\Delta t}{\tau}\right)
$$

This leads to an implicit numerical technique to solve for $C(t+\Delta t)$

$$
\begin{aligned}
C(t+\Delta t)= & \beta+(C(t)-\beta) \\
& \cdot \exp \left(\frac{-2 \Delta t}{\tau(t)+\tau(t+\Delta t)}\right)
\end{aligned}
$$

where

$$
\begin{aligned}
\beta= & \left(\frac{a(t)+a(t+\Delta t)}{2}\right) \\
& \cdot\left(\frac{\tau(t)+\tau(t+\Delta t)}{2}\right)
\end{aligned}
$$

Young and Boris recognize that evaluation of the exponential is computationally expensive and so they derive an approximate solution for $C(t+\Delta t)$ as

$$
\begin{aligned}
C(t+\Delta t)= & \beta+(C(t)-\beta) \\
& \cdot\left[\frac{\tau(t+\Delta t)+\tau(t)-\Delta t}{\tau(t+\Delta t)+\tau(t)+\Delta t}\right]
\end{aligned}
$$

When the time step $\Delta t$ is large compared with the characteristic time $\tau$ for the equation, the error introduced by this approximation converges to

$$
\text { error }=\mathrm{C}(\mathrm{t})-\beta
$$


Thus the Young and Boris technique applies a more stable solution to stiff equations, but application is limited to equations for which the error term defined by equation (15) is small. Performance analysis undertaken in the current study indicates that within the present application, the majority of the computational time is spent evaluating equilibrium conditions in the particle phase, and these calculations benefit from increased stability in the kinetic solver. As a result, use of equation (12) instead of equation (14) does not significantly increase the computational burden of each iteration. Furthermore, because equation (12) does not introduce an extra error term into the calculation, it can be applied to a larger fraction of the equation set, leading to increased stability and efficiency improvements in the equilibrium solution. To take advantage of these features, the numerical solution technique was modified to use equation (12) when integrating stiff equations. The definition of a stiff equation was also relaxed to include more of the equation set being integrated. Over- all, these changes increase the stability of the solution technique, allowing larger time steps to be taken, which leads to improved computational efficiency.

\section{Testing of Individual Model Components}

Gas-to-particle conversion and aqueous-phase chemical reaction processes are influenced by the composition of the particles on which those processes are initiated. Thus the model components describing these processes are tested to illustrate their sensitivity to the representation of the aerosol particles as an internal mixture vs. a source-oriented external mixture. Model components describing physical processes such as emissions, transport and deposition are not directly affected by the representation of the airborne particles as a sourceoriented external mixture, so no further tests of these algorithms beyond those reported earlier are required.

Table 1. Results for Test of Alternative Aerosol Thermodynamics Models

\begin{tabular}{|c|c|c|c|c|c|c|}
\hline & \multicolumn{6}{|c|}{ Relative Humidity, \% } \\
\hline & 90 & 80 & 70 & 60 & 50 & 40 \\
\hline \multicolumn{7}{|c|}{ Nitrate as $\mathrm{NO}_{3}^{-}\left(\mu \mathrm{g} \mathrm{m}^{-3}\right)$} \\
\hline \multicolumn{7}{|l|}{ Internal mixture } \\
\hline SCAPE ${ }^{\mathbf{a}}$ & 4.8 & 1.9 & 0.9 & 0.4 & 0.1 & 0.2 \\
\hline original $\mathrm{AIM}^{\mathrm{a}}$ & 1.2 & 0.4 & 1.6 & 1.2 & 0.5 & 0.2 \\
\hline revised AIM $^{\mathrm{b}}$ & 1.1 & 0.25 & 0.03 & 0.01 & 0.02 & 0.01 \\
\hline revised $\mathrm{AIM}^{\mathrm{c}}$ & 1.5 & 0.3 & 0.04 & 0.03 & 0.02 & 0.02 \\
\hline \multicolumn{7}{|l|}{ External Mixture } \\
\hline revised AIM ${ }^{c, d}$ & 14.3 & 14.6 & 16.4 & 15.9 & 15.9 & 15.9 \\
\hline \multicolumn{7}{|c|}{ Ammonia as $N H_{4}^{+}\left(\mu g m^{-3}\right)$} \\
\hline \multicolumn{7}{|l|}{ Internal mixture } \\
\hline SCAPE $^{\mathrm{a}}$ & 10.5 & 10.5 & 10.5 & 10.5 & 10.5 & 10.5 \\
\hline original AIM $^{2}$ & 10.6 & 10.6 & 10.5 & 10.5 & 10.5 & 10.5 \\
\hline revised AIM $^{\mathrm{b}}$ & 10.6 & 10.6 & 10.6 & 10.6 & 10.5 & 10.5 \\
\hline revised $\mathrm{AIM}^{\mathrm{c}}$ & 10.5 & 10.6 & 10.6 & 10.6 & 10.5 & 10.5 \\
\hline \multicolumn{7}{|l|}{ External Mixture } \\
\hline revised $\mathrm{AIM}^{c, d}$ & 10.6 & 10.6 & 10.6 & 10.6 & 10.6 & 10.6 \\
\hline \multicolumn{7}{|c|}{ Chloride as $\mathrm{Cl}^{-}\left(\mu \mathrm{g} \mathrm{m}^{-3}\right)$} \\
\hline \multicolumn{7}{|l|}{ Internal Mixture } \\
\hline SCAPE ${ }^{\mathrm{a}}$ & 0.7 & 0.2 & 0.1 & 0.0 & 0.0 & 0.0 \\
\hline original AIM ${ }^{2}$ & 0.1 & 0.0 & 0.0 & 0.0 & 0.0 & 0.0 \\
\hline revised AIM $^{\mathbf{b}}$ & 0.11 & 0.01 & 0.0 & 0.0 & 0.0 & 0.0 \\
\hline revised AIM $^{c}$ & 0.11 & 0.01 & 0.0 & 0.0 & 0.0 & 0.0 \\
\hline \multicolumn{7}{|l|}{ External Mixture } \\
\hline revised $A_{I} M^{c, d}$ & 2.17 & 1.44 & 6.02 & 7.03 & 7.7 & 8.2 \\
\hline \multicolumn{7}{|c|}{ Water $\left(\mu g m^{-3}\right)$} \\
\hline \multicolumn{7}{|l|}{ Internal Mixture } \\
\hline SCAPE $^{a}$ & 218 & 110 & 74.4 & 55.9 & 15.3 & 4.61 \\
\hline original AIM ${ }^{\mathbf{a}}$ & 188 & 102 & 75.1 & 54.1 & 37.7 & 29.5 \\
\hline revised $\mathrm{AIM}^{\mathrm{b}}$ & 173 & 81.2 & 7.3 & 1.4 & 0.6 & 0.44 \\
\hline revised $\mathrm{AIM}^{\mathrm{c}}$ & 175 & 81.4 & 6.5 & 1.7 & 0.6 & 0.44 \\
\hline \multicolumn{7}{|c|}{$\begin{array}{l}\text { See text for initial gas and particle-phase composition. } \\
\text { a Results for case } 3 \text { of Kim et al. [1993]. } \\
\text { b Thermodynamic data for } \mathrm{NH}_{4} \mathrm{NO}_{3} \text { from Wagman et al. [1982]. } \\
\text { c Thermodynamic data for } \mathrm{NH}_{4} \mathrm{NO}_{3} \text { from Stelson and Seinfeld [1982]. } \\
\text { d } \mathrm{Na}^{+} \text {and } \mathrm{SO}_{4}^{2-} \text { present in separate particles. }\end{array}$} \\
\hline
\end{tabular}




\subsection{Gas-to-Particle Conversion in the Absence of Clouds or Fog}

Gas-to-particle conversion in the absence of clouds or fog is calculated with a modified form of the computer code AIM as described in section 2.4. Kim et al. [1993] present a comparison of the results produced by the original version of AIM to the results obtained from the gas/aerosol equilibrium model SCAPE by initializing both models with the same gas- and particle-phase chemical species concentrations and then running the original version of AIM until equilibrium is reached. This analysis is repeated using the revised version of AIM so that all three sets of results can be compared directly. In SCAPE calculations, activity coefficient estimates obtained by Kusik and Meissner's method will be used in the present work since this is the activity coefficient calculation method used in both the original and the revised version of AIM.

Test case 3 from Kim et al. [1993] represents an example where all of the ionic species considered by AIM are present in significant amounts. Intial particle-phase concentrations are $48.97 \mu \mathrm{g} \mathrm{m}^{-3}$ of $\mathrm{SO}_{\overline{4}}, 29.52 \mu \mathrm{g} \mathrm{m}^{-3}$ of $\mathrm{NO}_{3}^{-}, 9.1 \mu \mathrm{g} \mathrm{m}^{-3}$ of $\mathrm{Cl}^{-}, 10.59 \mu \mathrm{g} \mathrm{m}^{-3}$ of $\mathrm{NH}_{4}^{+}$, $5.9 \mu \mathrm{g} \mathrm{m}^{-3}$ of $\mathrm{Na}^{+}$, and $0.91 \mu \mathrm{g} \mathrm{m}^{-3}$ of $\mathrm{H}^{+}$, while all gas phase species are initialized to zero. Gaseous species then evolve from the particles until equilibrium is reached. For the purposes of illustration an external mixture calculation will be conducted in which this system is split into two groups of particles both with initial diameters of $1.0 \mu \mathrm{m}$. The first set of particles contains all the sodium/chloride, while the second set of particles contains all the sulfate/nitrate/ammonium as may be expected to be the case if freshly generated sea spray aerosol is mixed with sulfates and nitrates produced previously during long-distance transport of aged air pollution. Hydrogen ion is distributed appropriately to obtain charge balance. The equilibrium concentrations of volatile components in the particie phase predicted by each of the three aerosol process models at a temperature of $298 \mathrm{~K}$ and various relative humidities are summarized in Table 1.

The predictions made by all three aerosol process models appear to be very similar for the case of an internally mixed aerosol. Nonvolatile sulfate dominates this test system, pulling all available ammonia into the particle phase. This leaves insufficient ammonia in the gas phase to form either $\mathrm{NH}_{4} \mathrm{NO}_{3}(\mathrm{~s})$ or $\mathrm{NH}_{4} \mathrm{Cl}(\mathrm{s})$ in the particle phase. As a result, nitrate and chloride exist in the gas phase as $\mathrm{HNO}_{3}$ and $\mathrm{HCl}$ and as free ions in the aqueous shell surrounding the particles but never crystallize to form part of the solid core of the particle. The aerosol water content predicted by the original version of AIM matches predictions made by the revised version of AIM and the SCAPE model at high relative humidity but significantly overpredicts water content at low relative humidity, reflecting the inability of that model to crystallize solids under certain conditions.
In the case of an externally mixed aerosol, dramatic differences are seen for the predicted aerosol composition at equilibrium made by the revised version of AIM relative to the internally mixed aerosol representation of the same chemical system. The particle group containing the nonvolatile sulfate still draws all of the available ammonia into the particle phase, but separate particles containing the nonvolatile sodium also draw nitrate and chloride into the particle phase in an analogous fashion. This leads to a great increase in the predicted nitrate and chloride concentrations in the particle phase relative to the internally mixed aerosol calculation. This example illustrates one possible distortion of the atmospheric aerosol concentrations that could be produced by employing an internal mixture model under conditions where secondary formation processes are active.

\subsection{Gas-to-Particle Conversion in the Presence of Fog or Clouds}

The degree to which the ambient aerosol at Claremont, California is externally mixed has been studied experimentally by Zhang et al. [1993]. This experiment involved selecting a narrow range of particle sizes using a differential mobility analyzer (DMA), humidifying this classified aerosol and then measuring the modified size distribution of particles using a second DMA. Upon humidification, one group of particles grew rapidly to larger sizes while a second group containing more hydrophobic particles grew by a smaller amount, thereby creating a bimodal size distribution from initially monodisperse seed particles. The results of this experiment indicated that ambient submicron particles of the same size typically have distinctly different hygroscopic characteristics, strongly suggesting that the ambient particles consist of an external mixture. In order to test the operation of the fog model in the presence of an internally versus externally mixed representation of the atmospheric aerosol, a numerical experiment motivated by that conducted by Zhang et al. [1993] was performed. Gas- and particle-phase pollutant concentrations based on ambient conditions near the coast of Los Angeles at 0000 PST on August 28, 1987, were obtained from one of the trajectory simulations that will be presented in section 4 of this study. A narrow slice of the aerosol size distribution in the diameter range 0.3 $\mu \mathrm{m}$ to $0.5 \mu \mathrm{m}$ was then selected and exposed to an atmosphere with a water vapor supersaturation of $0.08 \%$, in one case with the aerosol represented as an internal mixture and in the second case with the aerosol represented as a source-oriented external mixture. The captured air parcel studied was spiked with $0.15 \mathrm{ppm} \mathrm{SO}_{2}$ in order to allow heterogenous sulfate formation to occur. Gas-phase photochemistry, gas and particle-phase deposition, and continuing emissions were not enabled during this test so that the effect of the internally versus externally mixed representations of the aerosol on the gas-to-particle conversion and aqueous-phase physical and chemical transformations during fog events could 
be examined directly. The initial particle-phase concentrations and major gas-phase concentrations specified for this test are found in Table 2. The initial size distribution of material in the particle phase and the evolution of this size distribution after 1 hour and 2 hours with no further inputs or losses is shown in Figure 1. Although water is not explicitly shown in these graphs, the size distributions of particle-phase chemical components are plotted at the equivalent wet particle diameters.

The results of this numerical experiment show that the internally mixed aerosol grows due to condensation of water, but the size distribution of particles remains nearly monodisperse since all particles of the same size have the same chemical composition and hygroscopic properties. The externally mixed aerosol splits into two distinct modes when exposed to the supersaturated air, reflecting different hygroscopic properties between particles of the same diameter. The mode with the smaller diameter consists of particles composed largely of less hygroscopic material such as primary organics and crustal material, while the mode with the larger diameter is comprised mainly of more hygroscopic material such as ammonium, sulfate, and nitrate. Such bimodal behavior during conditions when the atmosphere is supersaturated with respect to water vapor would affect particle removal by gravitational sedimentation, urban/regional visibility calculations during fogs, as well as global scale radiative transfer calculations involving clouds.

Aqueous phase chemical transformations lead to production of sulfate in the particle phase. No significant difference is seen between the total amount of sulfate produced within a fog seeded by an internally versus externally mixed aerosol under the conditions of the particular test case examined here.

\section{Trajectory Model Evaluation}

A comparison of the results produced by the external versus internal mixture models applied to the same air pollution episode requires an episode for which detailed information is available which describes meteorological conditions, gas and particulate-phase emissions, and ambient air quality. Because complete data sets of this type are extremely difficult and expensive to obtain, few air quality episodes have been characterized in such detail. The Southern California Air Quality Study (SCAQS) was a large cooperative air quality measurement program carried out in the South Coast Air Basin of California to collect information for the design and evaluation of air quality models [Lawson, 1990]. Eldering and Cass [1996] examined the SCAQS data taken during the summer of 1987 and determined that the data collected during the episode of August 27-28, 1987, at Claremont, California, are relatively complete and self-consistent. They then used a trajectory model having an internally mixed representation of the aerosol to predict the evolution of the particle size and composition distribution as well as visibility-related parameters for this episode. Since the present study builds on this previous work, trajectories ending at Claremont during the August 27-28, 1987, SCAQS episode also are used here as the basis for comparison of the results of calculations that use alternative representations of the extent of aerosol mixing. Air parcels are tracked over a period of 2 days, starting over the ocean and terminating at Claremont on August 28, 1987. Although the trajectory paths and model inputs used in this study are virtually identical with those used by Eldering and Cass [1996], the representation of the aerosol as a source-oriented external mixture and other model improvements result in different predictions for ambient air quality.

Table 2. Initial Conditions for Box Model of Fog Initiated on Nearly Monodisperse Aerosol in the Diameter Range $0.3 \mu \mathrm{m}-0.5 \mu \mathrm{m}$

\begin{tabular}{|c|c|c|c|}
\hline Particle-Phase Species ${ }^{\mathrm{a}}$ & $\begin{array}{l}\text { Concentration }{ }^{b} \\
\mu \mathrm{g} \mathrm{m}{ }^{-3} \text { air }\end{array}$ & Gas-Phase Species $^{a}$ & $\begin{array}{l}\text { Concentration } \\
\text { ppm }\end{array}$ \\
\hline $\mathrm{NH}_{4}^{+}(\mathrm{aq})$ & 14.3 & $\mathrm{NH}_{3}(\mathrm{~g})$ & $8.73 \times 10^{-4}$ \\
\hline $\mathrm{Cl}^{-}(\mathrm{aq})$ & 17.0 & $\mathrm{HCl}(\mathrm{g})$ & $7.33 \times 10^{-4}$ \\
\hline $\mathrm{NO}_{3}^{-}(\mathrm{aq})$ & 57.3 & $\mathrm{HNO}_{3}(\mathrm{~g})$ & $1.63 \times 10^{-3}$ \\
\hline $\mathrm{SO}_{4}^{=}(\mathrm{aq})$ & 129.7 & $\mathrm{SO}_{2}(\mathrm{~g})$ & $1.55 \times 10^{-1}$ \\
\hline $\mathrm{H}_{2} \mathrm{SO}_{3}(\mathrm{aq})$ & $2.38 \times 10^{-7}$ & $\mathrm{OH}(\mathrm{g})$ & $2.71 \times 10^{-9}$ \\
\hline $\mathrm{Na}^{+}(\mathrm{aq})$ & $1.55 \times 10^{-1}$ & $\mathrm{H}_{2} \mathrm{O}_{2}(\mathrm{~g})$ & $7.97 \times 10^{-4}$ \\
\hline $\mathrm{Cu}(\mathrm{I})(\mathrm{aq})$ & $2.10 \times 10^{-4}$ & $\mathrm{O}_{3}(\mathrm{~g})$ & $2.18 \times 10^{-6}$ \\
\hline $\mathrm{Cu}$ (II)(aq) & $1.80 \times 10^{-3}$ & $\mathrm{NO}(\mathrm{g})$ & $3.29 \times 10^{-2}$ \\
\hline $\mathrm{Fe}(\mathrm{II})(\mathrm{aq})$ & $1.11 \times 10^{-1}$ & $\mathrm{NO}_{2}(\mathrm{~g})$ & $6.62 \times 10^{-2}$ \\
\hline $\mathrm{Fe}(\mathrm{III})(\mathrm{aq})$ & $1.11 \times 10^{-1}$ & $\mathrm{NO}_{3}(\mathrm{~g})$ & $1.32 \times 10^{-11}$ \\
\hline $\operatorname{Mn}(\mathrm{II})(\mathrm{aq})$ & $1.74 \times 10^{-2}$ & $\mathrm{HNO}_{4}(\mathrm{~g})$ & $1.63 \times 10^{-6}$ \\
\hline $\operatorname{Mn}(I I I)(a q)$ & $3.48 \times 10^{-5}$ & $\mathrm{HCHO}(\mathrm{g})$ & $6.23 \times 10^{-3}$ \\
\hline Elemental carbon & $7.50 \times 10^{-2}$ & CHOCHO $(\mathrm{g})$ & $8.12 \times 10^{-5}$ \\
\hline Primary organics & 1.56 & $\mathrm{CH}_{3}(\mathrm{O}) \mathrm{CHO}(\mathrm{g})$ & $1.53 \times 10^{-4}$ \\
\hline Secondary organics & $2.39 \times 10^{-1}$ & HONO $(\mathrm{g})$ & $1.79 \times 10^{-4}$ \\
\hline Other & $1.58 \times 10^{-1}$ & $\mathrm{HO}_{2}(\mathrm{~g})$ & $2.50 \times 10^{-8}$ \\
\hline
\end{tabular}


Fog Initlated on Internally Mixed Aerosol

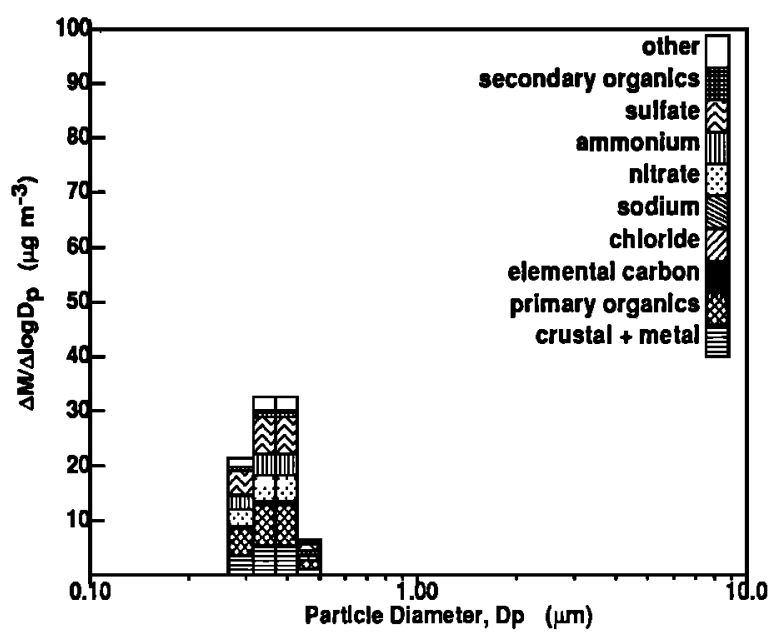

Internal Mixture Time $=60 \mathrm{~min}$.

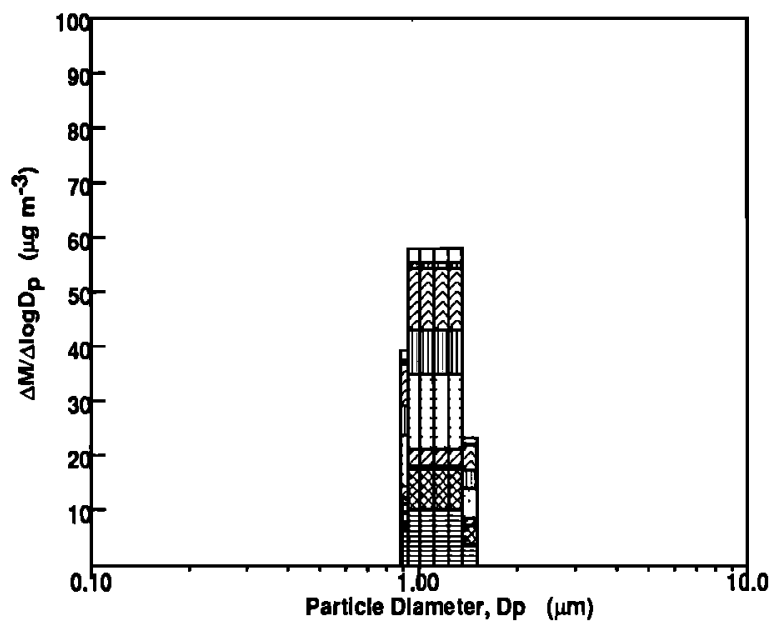

Internal Mixture Time $=\mathbf{1 2 0} \mathrm{min}$.

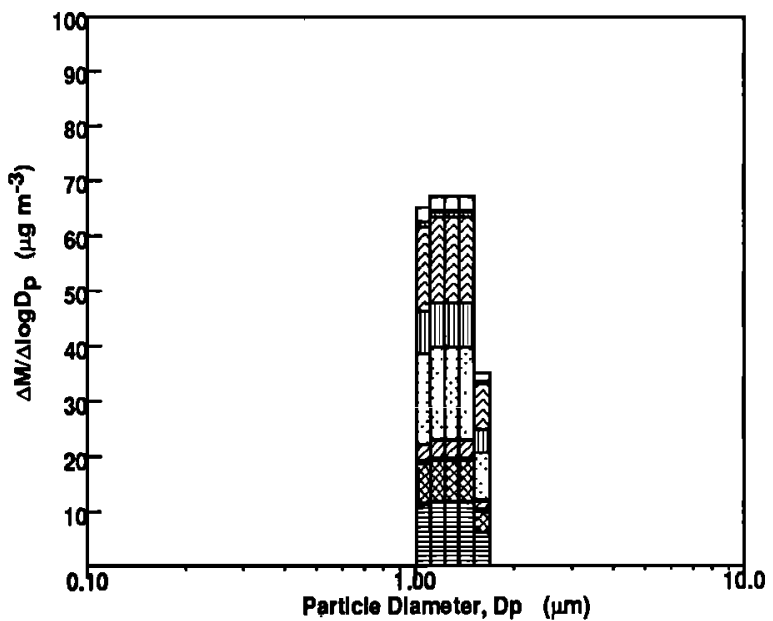

Fog Initiated on Externally Mlxed Aerosol

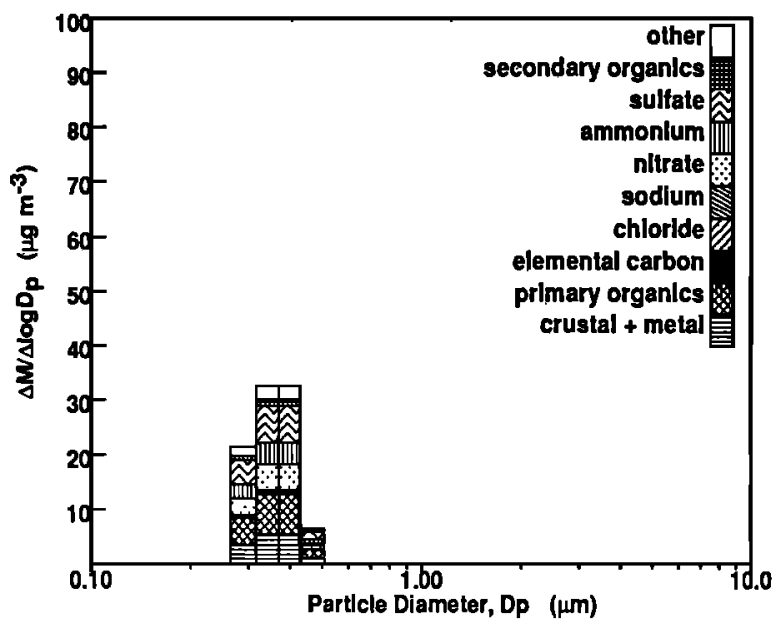

External Mixture Time $=60 \mathrm{~min}$.

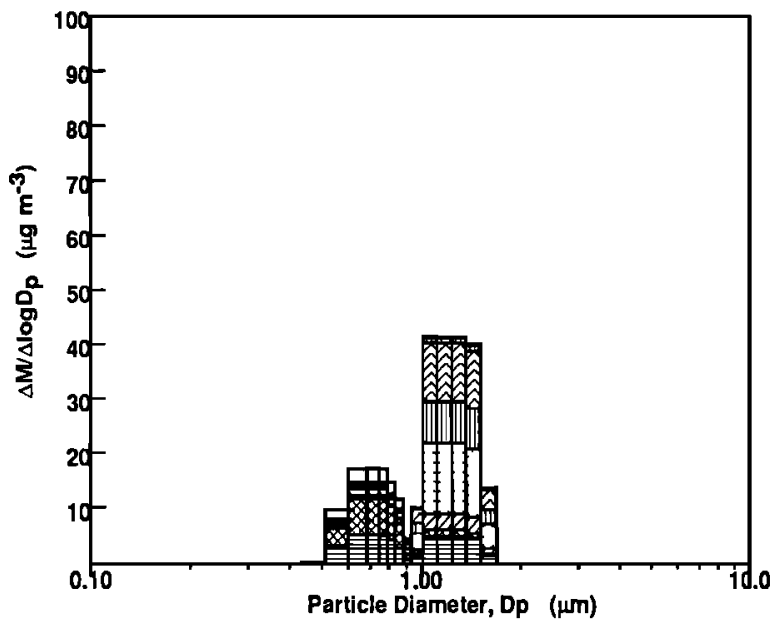

External Mixture Time $=120 \mathrm{~min}$.

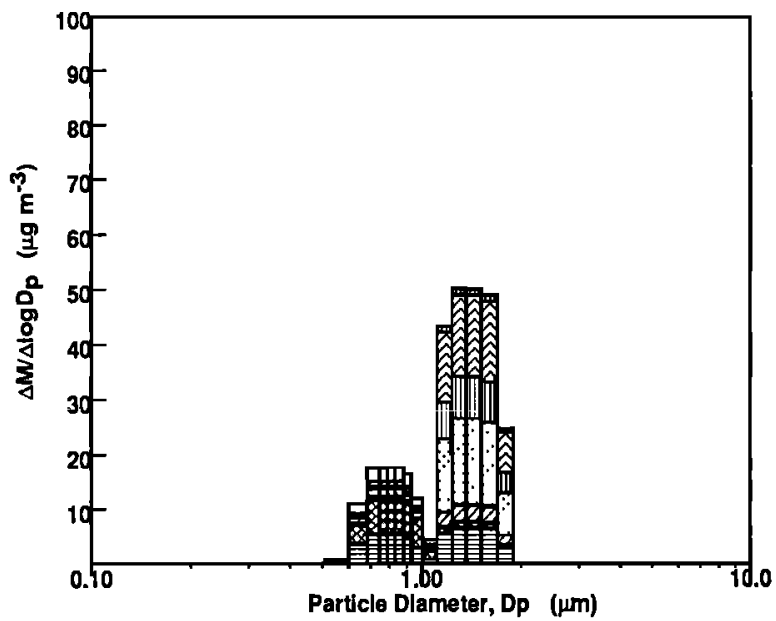

Figure 1. Initial size distribution of a nearly monodisperse aerosol separated from a representative Los Angeles coastal ambient aerosol and the evolution of its size distribution within a box model after 1 hour and 2 hours in the presence of fog and additional $\mathrm{SO}_{2}$ (see Table 2 for initial conditions). External mixture calculations produce a size distribution that is bimodal because of the different hygroscopic properties of particles having the same initial diameter. Particles are shown at their equivalent wet diameter, but water is not shown explicitly. 


\subsection{Meteorological Inputs}

The construction of meteorological inputs used for the August 27-28, 1987, episode closely follows the treatment described by Harley et al. [1993a] and Eldering and Cass [1996] except in the construction of the gridded fields describing fog events. In the present study, airports reporting fog were assigned a probability of 1.0 that fog was present, while airports reporting that fog was not present were assigned a fog probability of 0.0 . The probability that a fog event occurred at a give time and location was then computed by spatial interpolation between these locations according to the method of Goodin et al. [1979]. If a model grid square had a fog probability greater than 0.5 and an interpolated relative humidity value greater than $70 \%$, it was concluded that fog was present at that time and location between the ground and the base of the inversion layer. During periods when a fog event occurred, particles located below the inversion base were activated by exposure to an environment with a water vapor supersaturation of $0.08 \%$, while particles above the inversion base were assumed to be exposed to a high relative humidity that is nevertheless below the saturated conditions needed to form fog.

\subsection{Particulate-Phase Emission Inventory}

Mass emission rates, source locations, and temporal variation for $\mathbf{4 5 5}$ separate primary particle source types in southern California are provided by the California Air Resources Board (CARB) for the August 27-28, 1987, episode. Source activity levels (e.g., vehicle miles traveled by location, quantities of fuel burned, etc.) are retained but the mass emission rates per unit activity or the chemical composition profiles for $90 \%$ of the primary particle emissions are replaced by better information. Modifications to this inventory are made to account for the results of the source test program of Hildemann et al. [1991a, b]. More recent information concerning the emission rates for paved road dust and dust from construction and demolition sites is used as described by Eldering and Cass [1996]. In addition, emission rates for mobile sources are subdivided into rates for catalyst-equipped light-duty autos, catalystequipped light-duty trucks, catalyst-equipped mediumduty trucks, catalyst-equipped heavy-duty trucks, motorcycles, noncatalyst light-duty autos, noncatalyst light duty trucks, noncatalyst medium-duty trucks, noncatalyst heavy-duty trucks, diesel heavy-duty trucks, diesel urban buses, and tire wear to allow detailed emission profiles to be applied for each of these sources. The diurnal profile used for commercial food-cooking operations was modified to match that described by Gray [1986]. Once the total particulate mass emission rates for each source were specified, the chemical composition and size distribution of the emitted material was calculated using the emissions processing model described in section 2.1 .

\subsection{Gas-Phase Emission Inventory}

Mass emission rates and source locations for major gas-phase emission sources relevant to the August 2728,1987 , SCAQS episode were once again obtained from the California Air Resources Board. This inventory includes a description of $\mathrm{NO}_{x}, \mathrm{SO}_{x}, \mathrm{CO}$, and volatile organic compound (VOC) emissions along with the diurnal variation of each source. Carbon monoxide and organic gas hot exhaust emissions from on-road vehicles were scaled to 3 times the levels shown in the official CARB inventory based on the results of experiments conducted in a highway tunnel as described by Harley et al. [1993b]. The 1982 spatially and temporally resolved ammonia emission inventory for the South Coast Air Basin prepared by Gharib and Cass [1984], as summarized by Russell and Cass [1986], was used to represent $\mathrm{NH}_{3}$ emissions for the episode studied. Once the gas-phase mass emission rates of $\mathrm{NO}_{x}, \mathrm{SO}_{x}, \mathrm{CO}$, VOCs and $\mathrm{NH}_{3}$ for each source were specified, speciation of the VOC emissions was calculated using the gas-phase emission model described in section 2.1 .

\subsection{Initial Conditions}

Particle-phase initial conditions for the episode modeled are substantially identical to those shown by Eldering and Cass [1996] except for rearrangement of material within the size distribution to ensure charge balance for particles of all sizes. The species mass concentrations contained within the initial conditions are based on filter measurements made at San Nicolas Island during the August 27-28, 1987, period. The initial concentrations for various aerosol chemical species are $3 \mu \mathrm{g}$ $\mathrm{m}^{-3} \mathrm{Cl}^{-}, 2 \mu \mathrm{g} \mathrm{m}^{-3} \mathrm{Na}^{+}, 1 \mu \mathrm{g} \mathrm{m}^{-3} \mathrm{NO}_{3}^{-}, 1.4 \mu \mathrm{g} \mathrm{m}^{-3}$ $\mathrm{NH}_{4}^{+}, 3 \mu \mathrm{g} \mathrm{m}^{-3} \mathrm{SO}_{4}^{-}$, and $1 \mu \mathrm{g} \mathrm{m}^{-3}$ of organic material. The relative size distribution of the ionic species is based on impactor measurements made at Long Beach during SCAQS. The particles present due to initial conditions are injected into the trajectory model as the air mass crosses the coastline by setting the background concentrations in the model equal to the measured marine background values at that point in time. In the external mixture model, the particle-phase initial conditions are split into particles of two types to separate the freshly generated sodium chloride aerosol produced by sea spray from the aged ammonium nitrate and ammonium sulfate aerosol as shown in Figure 2. Initial conditions for relevant gas-phase pollutants were taken to be $113 \mathrm{ppb} \mathrm{CO}, 5 \mathrm{ppb} \mathrm{NO}, 40 \mathrm{ppb} \mathrm{O}, 11 \mathrm{ppb} \mathrm{MEK}$, $3.8 \mathrm{ppb} \mathrm{HCHO}$, and $3.5 \mathrm{ppb} \mathrm{CH}_{3} \mathrm{CHO}$ based on measurements made over the ocean during SCAQS [Harley et al., 1993b].

\subsection{Results}

Model results for the 24 trajectories arriving hourly at Claremont on August 28, 1987, predict the ambient concentration of major gas-phase pollutants as well as the concentration, size distribution, and chemical com- 
Initial Condition Part 1

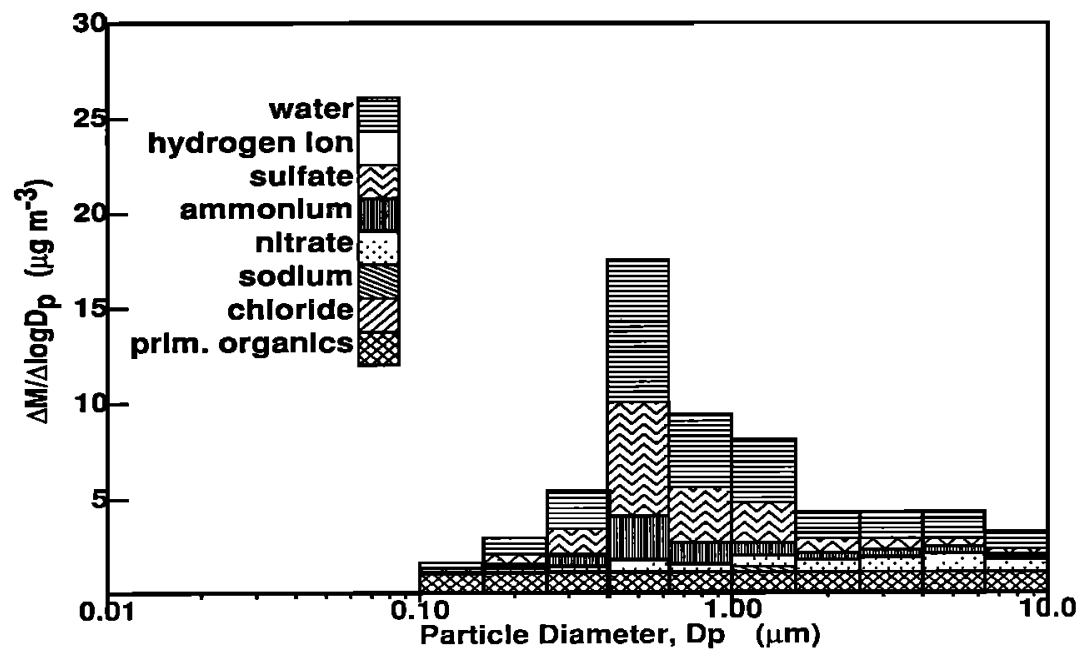

Initial Condition Part 2

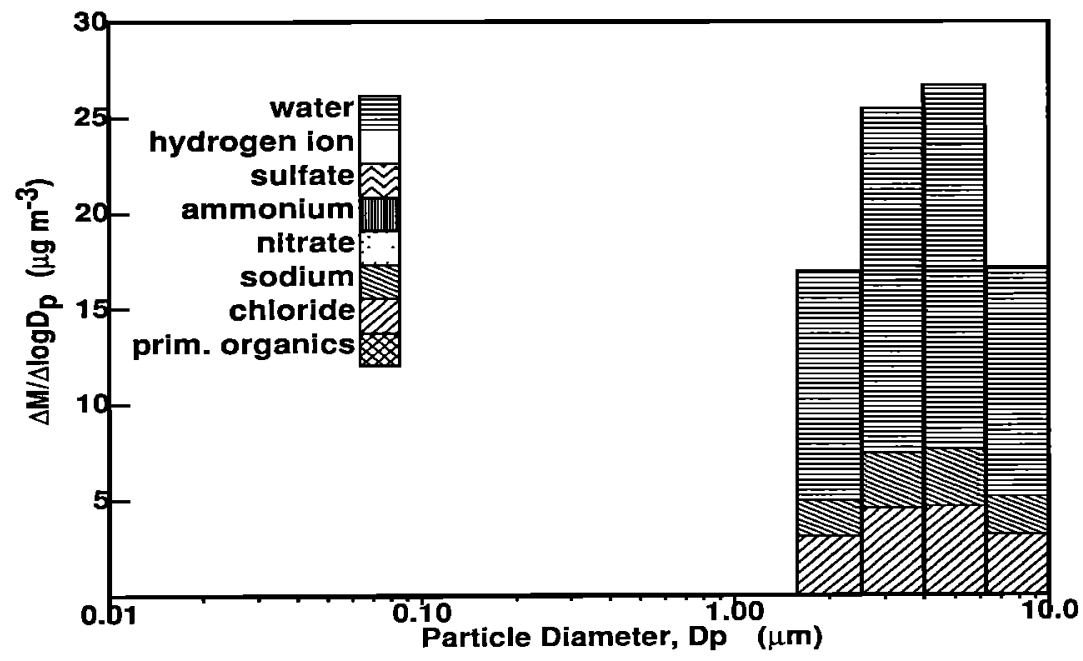

Figure 2. Aerosol mass distributions, $\Delta M / \Delta \log D_{p}$, describing initial conditions over the ocean for trajectories ending at Claremont, California, on August 28, 1987. During external mixture calculations, aged ammonium nitrate and ammonium sulfate aerosol is tracked as existing in particles that are separate from the freshly generated sodium chloride aerosol produced by sea spray.

position of particle-phase species. In the following sections, results calculated using the source-oriented external mixture representation of the aerosol will be compared to ambient measurements and then to results produced when the aerosol is represented as an internal mixture.

4.5.1. Gas-phase species. Gas-phase concentrations for $\mathrm{O}_{3}, \mathrm{NO}_{2}, \mathrm{NH}_{3}$, and $\mathrm{HNO}_{3}$, calculated using the source-oriented external mixture model, are substantially identical to those calculated using the internal mixture model. Both calculations underpredict peak $\mathrm{O}_{3}$ concentrations, matching the general trend for the August 28, 1987, Claremont SCAQS episode noted by Eldering and Cass [1996] and Harley et al. [1993a]. Predicted $\mathrm{NO}_{2}$ concentrations fall between the range of values reported by two collocated $\mathrm{NO}_{2}$ monitors with some overprediction during the nighttime hours. $\mathrm{HNO}_{3}$ measurements are 0 to $5 \mathrm{ppb}$ during the early morning and late night hours and reach a peak value of approximately $20 \mathrm{ppb}$ during the 0900-1300 PST SCAQS sampling period. This trend is generally well matched by model predictions. Both measured and predicted $\mathrm{NH}_{3}$ concentrations are of the order of a few parts per billion, with modeled results slightly higher than the measurements for all sampling periods. See Eldering and Cass [1996] for a graphical display of typical gas-phase species results.

4.5.2. Particle-phase species. Measurements of particle-phase pollutant concentrations at Claremont during the August 28, 1987, SCAQS episode were made using a filter-based SCAQS sampler [Fitz et al., 1989], a nine stage Berner impactor [John et al., 1990], and a micro-orifice uniform deposit impactor [Zhang et al., 1993]. The SCAQS sampler was operated over the full 
24 hour period in five discrete time intervals of 0000 0500 PST, 0500-0900 PST, 0900-1300 PST, 1300-1700 PST, and 1700-2400 PST. The impactors were operated during all but the first of these sampling periods. Model results are presented at the particle sizes obtained after removing all particle-phase water, recalculating the particle density based on the remaining chemical components, and then adjusting the particle diameter so that particle-phase mass, number count, density, and volume are in agreement. This is done because it has been previously determined that the instruments used to measure particle size distributions at Claremont dried out the aerosol while making their measurements [Eldering et al., 1994].

4.5.3. Bulk chemical composition. A comparison of the observed particle-phase concentrations to the model results produced by the internal and sourceoriented external mixture models is shown in Table 3. Model results for total particulate matter smaller than $10 \mu \mathrm{m}$ diameter (PM10 mass) and smaller than $2.5 \mu \mathrm{m}$ diameter (PM2.5 mass) produced by using both models differ by less than $1.8 \%$. The elemental carbon (EC) and organic carbon (OC) results shown in Table 3 overpredict observed values by a small amount, $0.52 \mu \mathrm{g} \mathrm{m} \mathrm{m}^{-3}$ for EC and $2.31 \mu \mathrm{g} \mathrm{m}^{-3}$ for OC. The mean PM10 concentration is also overpredicted but is within $13 \%$ of the observed value.

Predictions for $\mathrm{SO}_{4}^{-}, \mathrm{NH}_{4}^{+}, \mathrm{NO}_{3}^{-}$, and $\mathrm{Na}^{+}$made by the internal mixture and source-oriented external mixture models are slightly lower than observations. The internal mixture and external mixture model results differ by $0.75 \mu \mathrm{g} \mathrm{m}^{-3}$ for $\mathrm{NO}_{3}^{-}$to $0.15 \mu \mathrm{g} \mathrm{m} \mathrm{g}^{-3}$ for $\mathrm{NH}_{4}^{+}$ with the external mixture results always closer to the observed values. The underprediction of $\mathrm{Na}^{+}$concentrations is most likely related to imperfect initial conditions supplied to the model as described by Eldering and Cass [1996]. Overall, the predicted bulk concentra- tions of all the particle-phase ionic species appear to be in good agreement with measurements made with the SCAQS sampler for the episode under consideration.

4.5.4. Impactor results. A comparison of the source-oriented external mixture model results to the impactor measurements for the 0900-1300 PST sampling period is shown in Figure 3. Internal mixture model results are also shown for chemical species where they differ from the source-oriented external mixture calculations at that time period.

Impactor measurements and model predictions for elemental carbon during the 0900-1300 PST sampling period agree well, a result consistent with that obtained by Eldering and Cass [1996]. Both the predicted and the measured elemental carbon mass distribution has a single mode located between $0.1 \mu \mathrm{m}$ and $1.0 \mu \mathrm{m}$ with a peak located at approximately $0.2 \mu \mathrm{m}$ to $0.3 \mu \mathrm{m}$ diameter. Model predictions for organic carbon also match observations in terms of the shape of the size distribution and location of the peak, but model results show significantly more organic carbon than that measured by the impactor. Eldering and Cass [1996] describe a similar trend in their results and go on to note that the measurements for organic carbon made by the impactor are significantly lower than the measurements made by the SCAQS sampler, indicating an inconsistency in the measured data.

Impactor measurements for sodium show increasing mass concentrations with increasing particle diameter, reflecting the sea-salt origin of this chemical component. Model predictions match observations fairly well when it is considered that initial conditions for sodium over the ocean are known on the average for this day but not for each separate trajectory.

The sulfate and ammonium ion size distributions measured by the Berner impactors each have a single mode in the $0.1 \mu \mathrm{m}-1.0 \mu \mathrm{m}$ range with a peak located

Table 3. Comparison of Model Results to Filter-Based Ambient Measurements From the SCAQS Sampler at Claremont on August 28, 1987

\begin{tabular}{|c|c|c|c|c|c|c|c|c|}
\hline Case & $\begin{array}{c}\text { PM2.5 EC } \\
{\left[_{\text {mean }]^{\mathrm{a}}}\right.} \\
\text { bias }^{\mathrm{b}} \\
\text { (s.d.) }^{\mathrm{c}}\end{array}$ & $\begin{array}{c}\mathrm{OC} \\
\text { (PM2.5) }\end{array}$ & $\begin{array}{c}\mathrm{SO}_{4}^{\overline{-}} \\
(\mathrm{PM} 2.5)\end{array}$ & $\begin{array}{c}\mathrm{NH}_{4}^{+} \\
(\mathrm{PM} 2.5)\end{array}$ & $\begin{array}{c}\mathrm{NO}_{3}^{-} \\
\left(\mathrm{PM}^{2.5}\right)\end{array}$ & $\begin{array}{c}\mathrm{Na}^{+} \\
\text {(PM10) }\end{array}$ & $\begin{array}{c}\text { Mass } \\
\text { (PM2.5) }\end{array}$ & $\begin{array}{c}\text { Mass } \\
\text { (PM10) }\end{array}$ \\
\hline $\begin{array}{c}\text { Observed } \\
\text { mean }\end{array}$ & {$[3.17]$} & {$[20.80]$} & {$[7,06]$} & [6.71] & [14.10] & [1.45] & {$[60.18]$} & {$[96.26]$} \\
\hline $\begin{array}{l}\text { Internal } \\
\text { mixture }\end{array}$ & $\begin{array}{c}{[3.69]} \\
0.52 \\
(1.71)\end{array}$ & 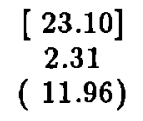 & $\begin{array}{c}{[5.60]} \\
-1.46 \\
(2.68)\end{array}$ & $\begin{array}{c}{[4.75]} \\
-1.96 \\
(2.50)\end{array}$ & $\begin{array}{c}{[10.75]} \\
-3.35 \\
(7.77)\end{array}$ & $\begin{array}{c}{[0.90]} \\
-0.55 \\
(0.16)\end{array}$ & $\begin{array}{c}{[73.61]} \\
13.43 \\
(31.11)\end{array}$ & $\begin{array}{c}{[109.09]} \\
12.84 \\
(46.50)\end{array}$ \\
\hline $\begin{array}{c}\text { External } \\
\text { mixture }\end{array}$ & $\begin{array}{c}{[3.69]} \\
0.52 \\
(1.70)\end{array}$ & $\begin{array}{c}{[23.15]} \\
2.36 \\
(11.92)\end{array}$ & $\begin{array}{c}{[6.04]} \\
-1.02 \\
(1.86)\end{array}$ & $\begin{array}{c}{[4.90]} \\
-1.82 \\
(2.33)\end{array}$ & $\begin{array}{c}{[11.50]} \\
-2.60 \\
(7.83)\end{array}$ & $\begin{array}{c}{[1.12]} \\
-0.33 \\
(0.16)\end{array}$ & 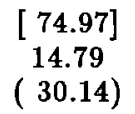 & $\begin{array}{c}{[108.97]} \\
12.71 \\
(44.88)\end{array}$ \\
\hline
\end{tabular}

SCAQS, southern California air quality study.

a Unweighted mean of five pairs of predictions and observations corresponding to the five sampling periods $\left(\mu \mathrm{g} \mathrm{m}^{-3}\right)$.

b Predicted-observed $\left(\mu \mathrm{g} \mathrm{m}^{-3}\right)$.

c Standard error of residuals $\left(\mu \mathrm{g} \mathrm{m}^{-3}\right)$. 

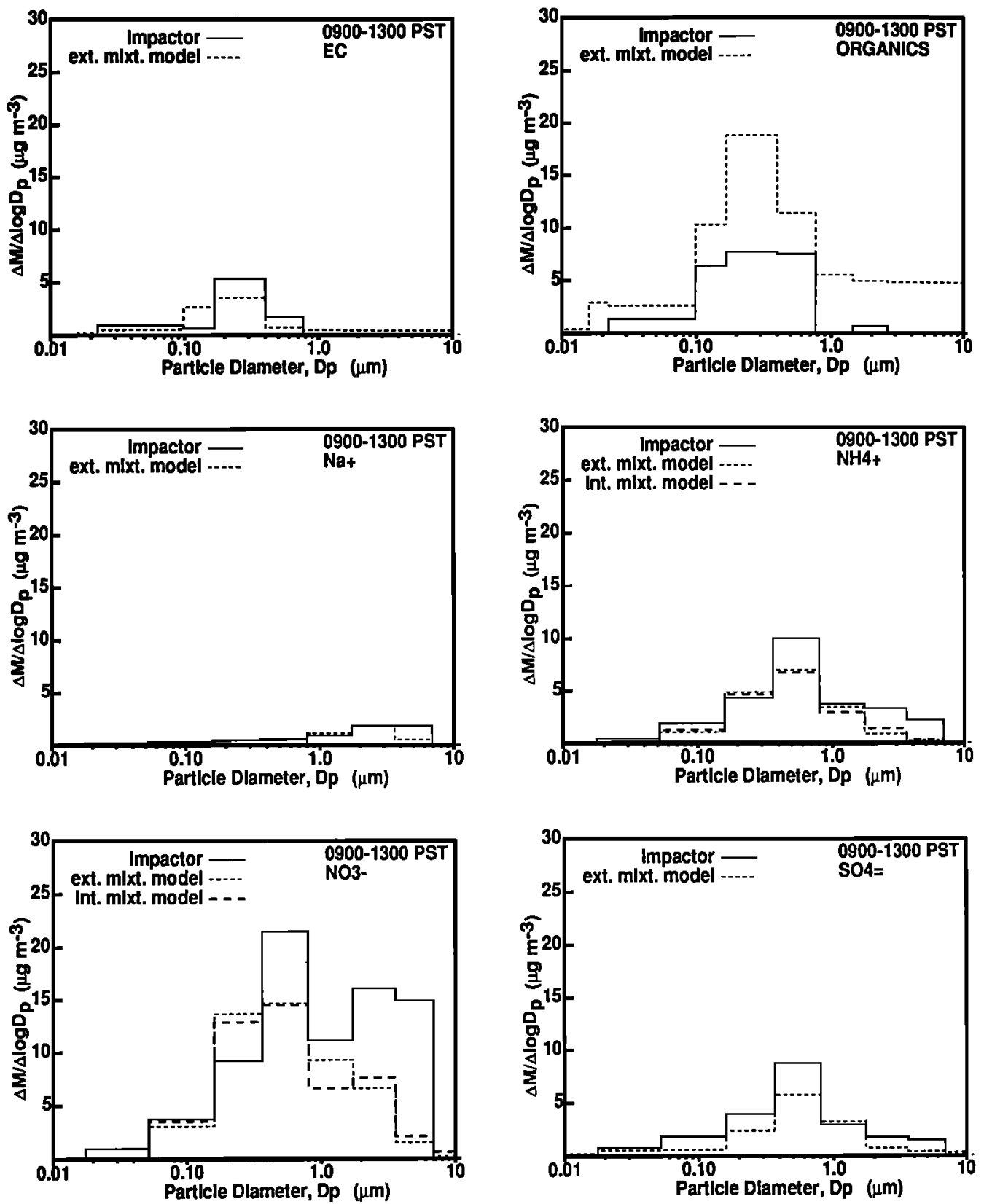

Figure 3. Model predictions of the mass distribution, $\Delta M / \Delta \log D_{p}$, of individual chemical species compared to impactor measurements made during the sampling period 0900-1300PST on August 28, 1987, at Claremont, California. Internal mixture model results are similar to external mixture model results for all species except for $\mathrm{NH}_{4}^{+}$and $\mathrm{NO}_{3}^{-}$.

at approximately $0.5 \mu \mathrm{m}-0.7 \mu \mathrm{m}$ diameter. Model results are in good agreement with these observations except for a slight underprediction of values right at the peak in the size distribution.

Nitrate aerosol concentration predictions for the source-oriented external mixture model and internal mixture model differ from each other. Both models underpredict nitrate aerosol in particles larger than $1 \mu \mathrm{m}$ diameter in part because the $\mathrm{Na}^{+}$concentration prediction in the largest particle sizes is too low due to the imprecision with which the marine aerosol initial con- ditions are known. The $\mathrm{Na}^{+}$concentrations in the initial conditions are due to $\mathrm{NaCl}$ aerosol produced by sea spray. The production rate of these particles is expected to be a strong function of wind speed and therefore is likely to vary from hour to hour and from trajectory to trajectory in ways that cannot be represented exactly by the 24 hour average $\mathrm{Na}^{+}$value computed from the SCAQS data. Nitrate aerosol concentrations in the external mixture case overall are higher than those for the internal mixture, and this advantage of the external mixture calculation would be expected to be even 
more pronounced if the larger amount of $\mathrm{Na}^{+}$actually present in the atmosphere were present in the model, as the test case of section 3.1 of this paper shows.

4.5.5. Aerosol size and composition distribution. A comparison of the model results to plots of $\Delta V / \Delta \log d_{p}$ obtained from electronic particle size distribution measurement instruments and filter samplers at 0700 PST and 1200 PST is shown in Figure 4. The ambient measurements shown here over the size range from $0.01 \mu \mathrm{m}$ to $1 \mu \mathrm{m}$ particle diameter are a composite constructed from TSI electrical aerosol analyzer (EAA), and laser optical particle counter (OPC) data as described by Eldering et al. [1994]. The response of those instruments falls off above $1 \mu \mathrm{m}$ particle diameter; the measured aerosol volume shown between $2.5 \mu \mathrm{m}$ and $10 \mu \mathrm{m}$ is obtained from the difference between SCAQS sampler PM10 versus PM2.5 filters and conveys no information other than the total aerosol volume in that size range. The chemically resolved size distributions predicted by both the internal and the source-oriented external mixture models are shown by grouping all particles having a diameter that falls within the particle diameter intervals reported by the electronic size distribution monitors. For both the hours under consideration the ambient data clearly show a bimodal mass distribution in the size range between $0.1 \mu \mathrm{m}$ and 1.0 $\mu \mathrm{m}$ as described by John et al. [1990] and Hering et al. [1997]. The external mixture model predicts this bimodal feature routinely as seen for both 0700 PST and 1200 PST, but the internal mixture calculation predicts only a single separate peak in the $0.1 \mu \mathrm{m}-1 \mu \mathrm{m}$ diameter range for 1200 PST.

4.5.6. Degree of external mixing. The big difference between the source-oriented external mixture model and the internal mixture model is that only the external mixture model can predict chemical composition differences between particles of the same general size. Plate 1 shows the source-oriented external mixture model representation of the ambient aerosol at Claremont, California, on August 28, 1987, at 1200 PST. Each of the pie charts in Plate 1 illustrates the composition of a single particle from one of the independent particle groups tracked by the source-oriented external mixture model. The size of each pie chart is proportional to the log of the actual particle diameter. The diameter of each particle is shown below the plot, while the number concentration of all particles of that type and size is shown above. The particle types are sorted such that the most numerous particles of each size appear toward the top of each column in Plate 1.

Plate 1 shows that the source-oriented external mixture calculation represents ambient particles with a diameter of approximately $0.013 \mu \mathrm{m}$ using five types of particles with unique chemical composition. Number concentrations for some of these very small particles may be above $10^{4} \mathrm{~cm}^{-3}$. Some of these very fine particles are composed mainly of elemental/organic carbon, while other particles of the same size have significant sulfate and metals concentration. Particles in the diameter range from $0.1 \mu \mathrm{m}$ to $10.0 \mu \mathrm{m}$ show the greatest diversity in terms of chemical composition and degree of external mixing with up to 10 unique particle types existing at the same approximate diameter. Some particles in this size range are seen to be composed primarily of organic carbon and crustal/metal material, while others have a large ionic species content. Particles with an inert core and a coating of ammonium / nitrate / sulfate are common between $0.1 \mu \mathrm{m}-1.0 \mu \mathrm{m}$ particle diameter. At larger sizes, particles containing sodium/nitrate are seen to exist separately from particles composed primarily of crustal material.

\section{Conclusions}

An atmospheric aerosol processes model has been constructed which is capable of representing the airborne particle complex as a source-oriented external mixture in which particles of the same size have different chemical compositions determined by the source from which they were initially emitted. These particles evolve separately in the atmosphere as they are affected by transport, deposition, gas-to-particle conversion, and aqueous phase chemical reaction. Tests cases presented in Figure 1 and Table 1 indicate that representation of the atmospheric aerosol as an internal mixture in which all particles of the same size have the same chemical composition can distort aerosol size and composition distributions during conditions when significant amounts of sulfate and sodium exist in externally mixed particles of the same size and when externally mixed particles containing material with different hygroscopic properties are exposed to high relative humidity.

Model evaluation against ambient data taken at Claremont, California, during the August 28, 1987, episode of the Southern California Air Quality Study indicates that ambient concentrations of particle-phase species can be successfully predicted both in terms of bulk properties and size-resolved chemical composition. Sourceoriented external mixture calculations predict small differences in particle-phase concentrations of $\mathrm{NH}_{4}^{+}, \mathrm{NO}_{3}^{-}$, and $\mathrm{Na}^{+}$relative to internal mixture results. The source-oriented external mixture model routinely produces an aerosol volume distribution at Claremont which is distinctly bimodal within the accumulation mode size range from $0.1 \mu \mathrm{m}$ to $1.0 \mu \mathrm{m}$ particle diameter, which matches field experimental observations, while the same model employing an internal mixture representation of the aerosol at times does not retain the observed bimodal distribution.

At very fine particle sizes close to $0.01 \mu \mathrm{m}$ diameter, numbers of largely carbonaceous particles are predicted to coexist at Claremont with separate particles containing largely sulfates and metals. In the size range between $0.1 \mu \mathrm{m}$ and $1.0 \mu \mathrm{m}$ particle diameter, a very large number of particles of highly diverse composition 
Model Results At Hour 0700 PST

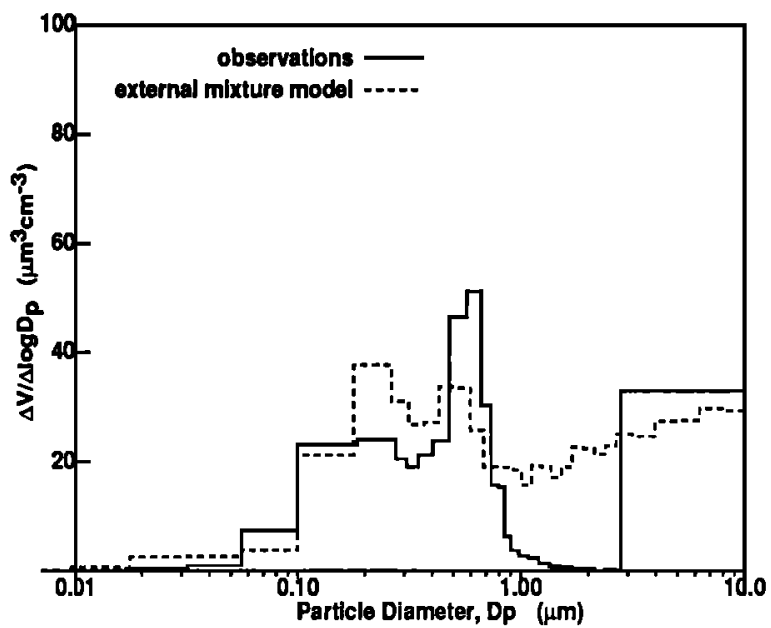

External Mixture Model Results At Hour 0700 PST

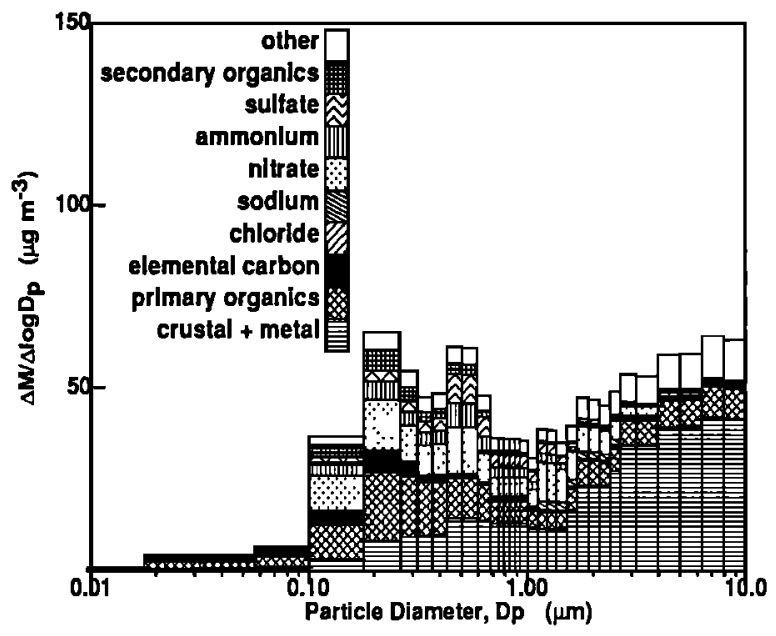

Internal Mlxture Model Results At Hour 0700 PST

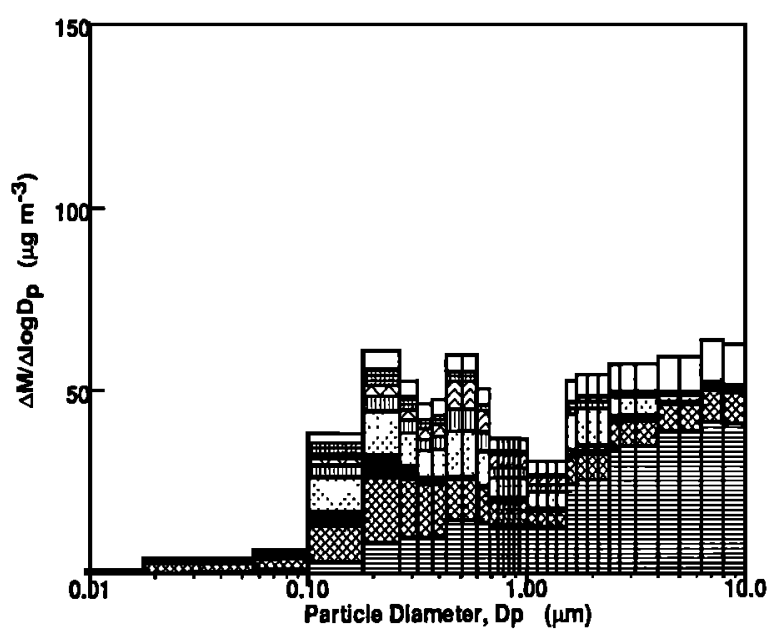

Model Results At Hour 1200 PST

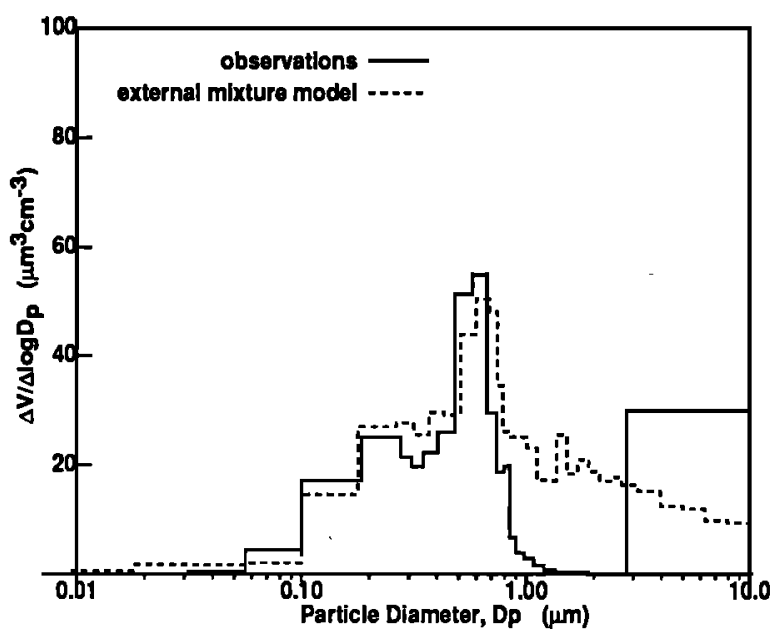

External Mlxture Model Results At Hour 1200 PST

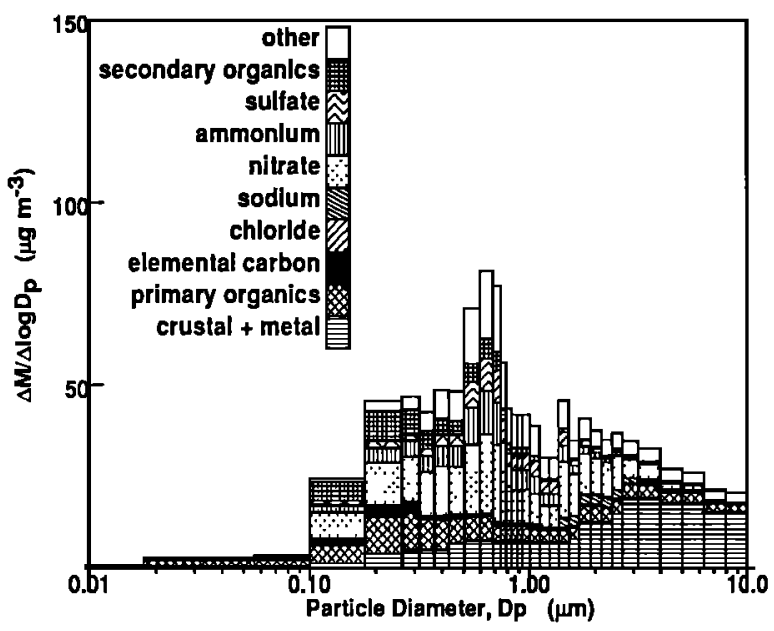

Internal Mixture Model Results At Hour 1200 PST

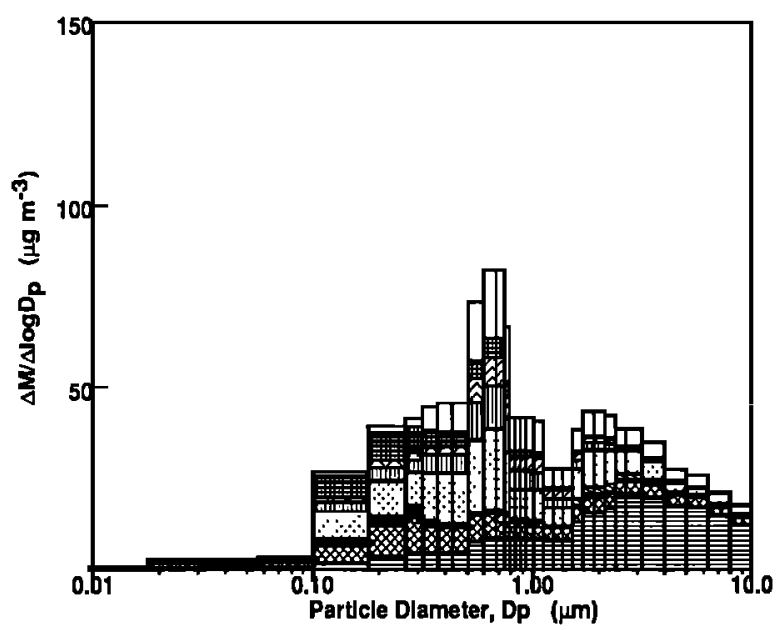

Figure 4. Comparison of measured and predicted size and composition distributions produced by the source-oriented external mixture model and the internal mixture model for 0700PST and 1200PST on August 28, 1987, at Claremont, California. Observed aerosol size distributions were measured using electrical aerosol analyzers, optical particle counters, and filter samplers. Comparison of results produced using internal mixture and source-oriented external mixture models show loss of the peak at a diameter of approximately $0.3 \mu \mathrm{m}$ at 1200PST in the internal mixture model. 


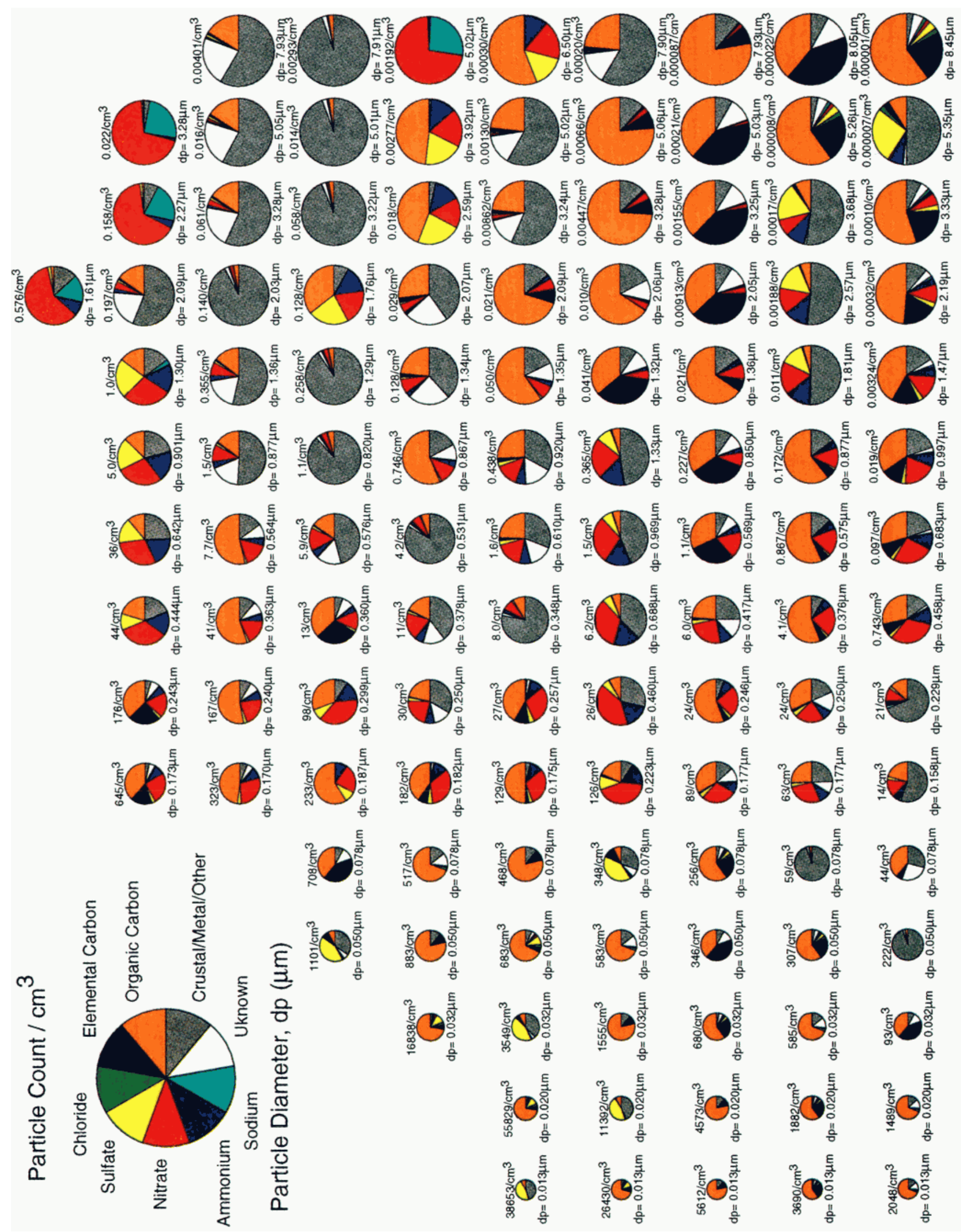


are found to accumulate as sulfate, nitrate, and secondary organic aerosol components lay coatings down onto seed particles having different initial core compositions. In relatively large particle sizes above 1.0 $\mu \mathrm{m}$ diameter, marine aerosol is transformed to produce $\mathrm{NaNO}_{3}$-containing particles that exist separately from mineral particles. The ability to predict the composition of individual particles is expected to have applications including explanation of the particle-to-particle differences seen by time-of-flight mass spectrometers that measure single-particle composition, the design of realistic test atmospheres for inhalation toxicology studies, support of accurate light scattering and absorption calculations, and more accurate predictions of aerosol response to changes in relative humidity.

The method described in the current study is theoretically applicable in an Eulerian grid-based model provided that the particle categories are defined so narrowly that particles with the same core properties (e.g., source), same approximate diameter, and possibly same age since emission to the atmosphere are present in adjacent grid cells. Whether or not one finds this formulation practical within a grid model depends on the availability of sufficient computational resources. Since computers are advancing very rapidly, we believe that such models will soon be practical.

Acknowledgments. This research was supported by a grant from the Caltech Center for Air Quality Analysis.

\section{References}

Binkowski, F. S., and U. Shankar, The regional particulate matter model 1. Model description and preliminary results, J. Geophys. Res., 100, 26191-26209, 1995.

Carter, W. P. L., A detailed mechanism for the gas-phase atmospheric reactions of organic compounds, Atmos. Environ., 24A, 481-518, 1990.

Chapra, S. C., and R. P. Canale, Numerical Methods For Engineers, 2nd ed., McGraw-Hill, New York, 1988.

Charlson, R. J., S. E. Schwartz, J. M. Hales, R. D. Cess, J. A. Coakley, J. E. Hansen, and D. J. Hofmann, Climate forcing by anthropogenic aerosols, Science, 255, 423-430, 1992.

Dreher, K. L., R. H. Jaskot, J. R. Lehmann, J. H. Richards, J. K. McGee, A. J. Ghio, and D. L. Costa, Soluable transition metals mediate residual oil fly ash induced acute lung injury, J. Toxicol. Environ. Health, 50, 285-305, 1997.

Eldering, A., and G. R. Cass, Source-oriented model for air pollutant effects on visibility, J. Geophys. Res., 101, 19,343-19,369, 1996.

Eldering, A., G. R. Cass, and K. C. Moon, An air monitoring network using continuous size distribution monitors: Connecting pollutant properties to visibility via Mie scattering calculations, Atmos. Environ., 28, 2733-2749, 1994.
Erel, Y., S. O. Pehkonen, and M. R. Hoftmann, Redox chemistry of iron in fog and stratus clouds, J. Geophys. Res., $98,18,423-18,434,1993$.

Fitz, D. R., M. Chan, G. R. Cass, D. R. Lawson, and L. Ashbaugh, A multi-component size-classifying aerosol and gas sampler for ambient air monitoring, paper presented at 82nd Annual Meeting, Air and Waste Manage. Assoc., Anaheim, Calif., 1989.

Gharib, S., and G. R. Cass, Ammonia emissions in the South Coast Air Basin, Open File Rep. 84-2, Environ. Qual. Lab., Calif. Inst. of Technol., Pasadena, 1984.

Goodin, W. R., G. J. McRae, and J. H. Seinfeld, A comparison of interpolation methods for sparse data: Application to wind and concentration fields, J. Appl. Meteorol., 18, 761-771, 1979.

Gray, H. A., Control of atmospheric fine primary carbon particle concentrations, Ph.D. thesis, Calif. Inst. of Technol., Pasadena, 1986.

Harley, R. A., M. P. Hannigan, and G. R. Cass, Respeciation of organic gas emissions and the detection of excess unburned gasoline in the atmosphere, Environ. Sci. Technol., 26, 2395-2408, 1992.

Harley, R. A., A. G. Russell, and G. R. Cass, Mathematical modeling of the concentrations of volatile organic compounds: Model performance using a lumped chemical mechanism, Environ. Sci. Technol., 27, 1638-1649, $1993 \mathrm{a}$.

Harley, R. A., A. G, Russell, G. J. McRae, G. R. Cass, and J. H. Seinfeld, Photochemical modeling of the Southern California Air Quality Study, Environ. Sci. Technol., 27, 378-388, $1993 \mathrm{~b}$.

Hering, S., A. Eldering, and J. H. Seinfeld, Bimodal character of accumulation mode aerosol mass distribution in southern California, Atmos. Environ., 31, 1-11, 1997.

Hildemann, L. M., G. R. Markowski, and G. R. Cass, Chemical composition of emissions from urban sources of fine organic aerosol, Environ. Sci. Technol., 25, 744-759, 1991 a.

Hildemann, L. M., G. R. Markowski, M. C. Jones, and G. R. Cass, Submicrometer aerosol mass distributions of emissions from boilers, fireplaces, automobiles, diesel trucks, and meat-cooking operations, Aerosol Sci. Technol., 14, 138-152, 1991b.

Hudischewskyj, A. B., and C. Seigneur, Mathemcatical modeling of the chemistry and physics of aerosols in plumes, Environ. Sci. Technol., 23, 413-421, 1989.

Jacob, D. J., Chemistry of $\mathrm{OH}$ in remote clouds and its role in the production of formic acid and peroxymonosulfate, J. Geophys. Res., 91, 9807-9826, 1986.

Jacob, D. J., E. W. Gottlieb, and M. J. Prather, Chemistry of a polluted boundary layer, J. Geophys. Res., 94, 12,975-13,002, 1989.

John, W., S. M. Wall, J. L. Ondo, and W. Winklmayr, Modes in the size distribution of atmospheric inorganic aerosol, Atmos. Environ., 24A, 2349-2359, 1990.

Kim, Y. P., J. H. Seinfeld, and P. Saxena, Atmospheric gasaerosol equilibrium II. Analysis of common approximations and activity coefficient calculation methods, Aerosol Sci. Technol., 19, 182-198, 1993.

Kusik, C. L., and H. P. Meissner, Electrolyte activity coefficients in inorganic processing, Fundam. Aspects $\mathrm{Hy}$ drometal. Processes AIChE Symp. Ser., $7_{4}(173), 14-20$, 1978.

Plate 1. Source-oriented external mixture model representation of the ambient aerosol at Claremont, California on August 28, 1987, at 1200PST. Each pie chart characterizes a single group of particles that are tracked separately by the model. The particle atmospheric concentration (number per $\mathrm{cm}^{3}$ air) is shown above each pie chart while the particle diameter $(\mu \mathrm{m})$ is shown below. 
Larson, S. M., G. R. Cass, K. J. Hussey, and F. Luce, Verification of image processing based visibility models, Environ. Sci. Technol., 22, 629-637, 1988.

Lawson, D. R., The southern California air quality study, $J$. Air Waste Manage. Assoc., 40, 156-165, 1990.

Ligocki, M. P., H. I. H. Liu, G. R. Cass, and W. John, Measurements of particle deposition rates inside southern California museums, Aerosol Sci. Technol., 13, 85-101, 1990.

McRae, G. J., W. R. Goodin, and J. H. Seinfeld, Development of a second-generation mathematical model for urban air pollution I. Model formulation, Atmos. Environ., 16, 679-696, 1982.

Middleton, P., and S. Burns, Denver air quality modeling study, in $A W M A$ Annual International Meeting, Air and Waste Manage. Assoc., Vancouver, B. C., Canada, 1991.

National Research Council(NRC), Protecting Visibility in National Parks and Wilderness Areas, Nat. Acad. Press, Washington, D. C., 1993.

Noble, C. A., and K. A. Prather, Real time measurement of correlated size and composition profiles of individual atmospheric aerosol-particles, Environ. Sci. Technol., 30, 2667-2680, 1996.

Oberdorster, G., R. M. Gelein, J. Ferin, and B. Weiss, Association of particulate air pollution and acute mortality, involvement of ultrafine particles?, Inhalation Toxicol., $\gamma$, 111-124, 1995.

Pandis, S. N., R. A. Harley, G. R. Cass, and J. H. Seinfeld, Secondary organic aerosol formation and transport, Atmos. Environ., 26A, 2269-2282, 1992.

Pandis, S. N., A. S. Wexler, and J. H. Seinfeld, Secondary organic aerosol formation and transport II. Predicting the ambient secondary organic aerosol size distribution, Atmos. Environ., 27A, 2403-2416, 1993.

Penner, J. E., R. J. Charlson, J. M. Hales, N. S. Laulainen, R. Leifer, T. Novakov, J. Ogren, L. F. Radke, and S. E. Schwartz, Quanitifying and minimizing uncertainty of climate forcing by anthropogenic aerosols, Bull. Am. Meteorol. Soc., 75, 375-400, 1994.

Pilinis, C., and J. H. Seinfeld, Development and evaluation of an Eulerian photochemical gas-aerosol model, Atmos. Environ., 22, 1985-2001, 1988.

Pruppacher, H. R., and J. D. Klett, Microphysics of Clouds and Precipitation, D. Reidel, Norwell, Mass., 1978.

Reid, R. C., J. M. Prausnitz, and B. E. Poling, The Properties of Gases and Liquids, 4th ed., McGraw-Hill, New York, 1987.

Robinson, R. A., and R. H. Stokes, Electrolyte Solutions, Academic, San Diego, Calif., 1955.

Russell, A. G., and G. R. Cass, Verification of a mathematical model for aerosol nitrate and nitric acid formation and its use for control measure evaluation, Atmos. Environ., 20, 2011-2025, 1986.

Russell, A. G., G. J. McRae, and G. R. Cass, Mathematical modeling of the formation and transport of ammonium nitrate aerosol, Atmos. Environ., 17, 949-964, 1983.
Russell, A. G., D. A. Winner, K. F. McCue, and G. R. Cass, Mathematical modeling and control of the dry deposition flux of nitrogen-containing air pollutants, Environ. Sci. Technol., 27, 2772-2782, 1993.

Schlesinger, R. B., Factors affecting the response of lung clearance systems to acid aerosols - Role of exposure concentration, exposure time and relative acidity, Environ. Health Perspect., 79, 121-126, 1989.

Seigneur, C., A. B. Hudischewskyj, J. H. Seinfeld, K. T. Whitby, J. R. Brock, and H. M. Barnes, Simulation of aerosol dynamics - A comparative review of mathematical-models, Aerosol Sci. Technol., 5, 205-222, 1986.

Seinfeld, J. H., Atmospheric Chemistry and Physics of Air Pollution, John Wiley, New York, 1986.

Slinn, S. A., and W. G. N. Slinn, Predictions for particle deposition on natural waters, Atmos. Environ., 14, 10131016, 1980.

Stumm, W., and J. J. Morgan, Aquatic Chemistry. An Introduction Emphasizing Chemical Equilibria in Natural Waters, 2nd ed., John Wiley, New York, 1981.

Tang, I. N., and H. R. Munkelwitz, Water activities, densities, and refractive indices of aqueous sulfates and sodium nitrate droplets of atmospheric importance, J. Geophys. Res., 99(D9), 18,801-18,808, 1994.

Wagman, D. D., W. H. Evans, V. Parker, R. H. Schumm, R. H. Harlow, S. M. Baily, K. L. Churney, and R. L. Nuttall, The NBS tables of chemical thermodynamic properties: Selected values for inorganic and $C_{1}$ and $C_{2}$ organic substances in SI units, J. Phys. Chem. Ref. Data, 11 (Suppl2), 1982.

Westall, J., MICROQL. A chemical equilibrium program in basic, Tech. Rep. CH-8600, Swiss Fed. Inst. of Technol. EAWAG, Duebendorf, Switzerland, 1979.

Wexler, A. S., and J. H. Seinfeld, Second-generation inorganic aerosol model, Atmos. Environ., 25A, 2731-2748, 1991.

Young, T., and J. Boris, A numerical technique for solving stiff ordinary differential equations associated with the chemical kinetics of reactive flow problems, J. Phys. Chem., 81, 2424-2427, 1977.

Zhang, X. Q., P. H. McMurry, S. V. Hering, and G. S. Casuccio, Mixing characteristics and water content of submicron aerosols measured in Los Angeles and at the Grand Canyon, Atmos. Environ., 27A, 1593-1607, 1993.

G. R. Cass and M. J. Kleeman, Environmental Engineering Science Department, California Institute of Technology, Pasadena, CA 91125. (e-mail: glen@eql.caltech.edu; mikek@eql.caltech.edu)

A. Eldering, Civil and Environmental Engineering, University of Iowa, Iowa City, IA 52242. (e-mail: eldering@icaen.uiowa.edu)

(Received January 29, 1997; revised April 18, 1997; accepted April 24, 1997.) 